\title{
EL NACIMIENTO DE LA ARQUITECTURA ESCOLAR ESPAÑOLA (1869-1886) ${ }^{\alpha}$ The early dawn of Spanish school architecture (1869-1886)
}

\section{Francisco Javier Rodríguez Méndez ${ }^{\mathrm{B}}$}

Fecha de recepción: 06/04/2020 • Fecha de aceptación: 08/07/2020

Resumen: A mediados del siglo XIX apenas había en España un solo pueblo que tuviera un edificio propio para escuela, estando las más de ellas alojadas en lugares carentes de las condiciones mínimas necesarias para la enseñanza. Durante el Sexenio Democrático (1868-1874), el liberalismo progresista impulsó las construcciones escolares, convocando para ello en 1869 un concurso de modelos de escuelas públicas de instrucción primaria. La trascendencia del certamen fue tal que, aunque el procedimiento seguido en él y su mismo fallo sean discutibles, podría ser considerado como el punto de partida de la arquitectura escolar española. Del concurso de 1869 derivan, de algún modo, la construcción de la Escuela Modelo para Madrid, las Escuelas Aguirre de Cuenca y Madrid y los Jardines de la Infancia, primera institución froebeliana en España, también en la capital.

Palabras clave: escuelas de instrucción primaria pública; arquitectura escolar; construcciones escolares; Francisco Jareño; Enrique M. ${ }^{a}$ Repullés y Vargas.

Abstract: In the middle of the 19th century scarcely a single town in Spain had its own school building, and most of the existing ones lacked the minimum conditions necessary for teaching. During the Sexenio Democrático (18681874), the progressive liberalist wing promoted the construction of school buildings, launching a call for models of primary state schools in 1869. The significance of this call was such that it could be considered as the early

\footnotetext{
${ }^{\alpha}$ Un avance del presente artículo fue presentado en la $41^{\mathrm{a}}$ International Standing Conference for the History of Education (ISCHE 41), celebrada en Oporto (Portugal) entre los días 17 y 20 de julio de 2019. Su título es deudor del que lleva el libro de Anne-Marie Châtelet dedicado a las escuelas primarias de París construidas entre 1870 y 1914 [Anne-Marie Châtelet, La naissance de l'architecture scolaire. Les écoles élémentaires parisiennes de 1870 à 1914. (París: Honoré Champion Editeur, 1999)].

B Escuela Politécnica Superior de Zamora, Universidad de Salamanca. Avenida del Cardenal Cisneros, 34 (Campus Viriato), 49029 Zamora, España. rodmen@usal.es (D) https://orcid.org/0000-00019212-9415
} 
dawn of Spanish school architecture, even if the ensuing process and results are debatable. The construction of the Escuela Modelo in Madrid, the Escuelas Aguirre in Cuenca and Madrid, and the Jardines de la Infancia - the first Froebelian institution in Spain, also located in the capital - can be considered to have derived from this contest from 1869.

Keywords: Primary state schools; School architecture; School buildings; Francisco Jareño; Enrique $M^{a}$ Repullés y Vargas.

\section{INTRODUCCIÓN}

El que hemos considerado período fundacional de la arquitectura escolar española se extiende entre los años 1869 y 1886. Es decir, desde el concurso de modelos de escuelas, convocado en los inicios del Sexenio Democrático, ${ }^{1}$ hasta la finalización de las más tardías de las construcciones escolares impulsadas en dicho período político.

Viñao Frago, quien ha dedicado una parte importante de su copiosa investigación al estudio del espacio escolar -y en particular al de los edificios escolares del sexenio²-, evidenciaba en 1993 que los estudios realizados en España en ese ámbito eran escasos y «no solían ir más allá de la mera información sobre los edificios [...], con el acompañamiento, en el mejor de los casos, de fotografías y planos». ${ }^{3}$ De un espíritu opuesto pretende estar imbuido el presente artículo, cuya intención es -en la medida de lo posible- analizar los edificios escolares generados en este período, ahondando en las fuentes que manejaron sus arquitectos y en las razones que fundamentaron sus proyectos.

\footnotetext{
${ }_{1}^{1}$ Etapa de la historia contemporánea española transcurrida desde el triunfo de la revolución de septiembre de 1868, que puso fin al reinado de Isabel II, hasta el pronunciamiento de diciembre de 1874, que supuso el inicio de la etapa conocida como Restauración borbónica.

2 Véanse: Antonio Viñao Frago, «Construcciones y edificios escolares durante el sexenio democrático (1868-1874)», Historia de la Educación 12-13 (1993-94): 493-534; «La escuela graduada: una nueva organización escolar y pedagógica», en Cien años de educación en España. En torno a la creación del Ministerio de Instrucción Pública y Bellas Artes, dirigido por Pedro Álvarez Lázaro (Madrid: Ministerio de Educación, Cultura y Deporte, Fundación BBVA, 2001), 363-388; «Templos de la patria, templos del saber: los espacios de la escuela y la arquitectura escolar», en Historia ilustrada de la escuela en España: dos siglos de perspectiva histórica, coord. Agustín Escolano Benito (Salamanca: Fundación Germán Sánchez Ruipérez, 2006), 47-72.
}

3 Antonio Viñao Frago, «El espacio escolar. Introducción», Historia de la Educación 12-13 (1993-94): 11-16. Se trata de la introducción a la sección monográfica de ese número, dedicada al espacio escolar en la historia, cuya coordinación corrió a cargo del autor. 
La idea inmanente en la convocatoria del concurso de 1869 era la de una elemental escuela-aula y no la de una escuela graduada -ya entonces demandada por los pedagogos-, entendida como conjunto de clases integradas en un solo edificio, en salas separadas y con su respectivo maestro cada una. ${ }^{4}$ Contrariamente, el modelo organizativo entonces dominante consistía en un espacio escolar único, de amplias dimensiones, donde se combinaban varios sistemas pedagógicos: el individual, el simultáneo, el mutuo o el mixto. ${ }^{5}$

Habría que esperar al cambio de siglo para que la escuela graduada de Cartagena, primera proyectada específicamente para tal fin, llegara a ser una realidad. Pero ello no significa que no se construyeran en España, con anterioridad, edificios escolares con varias escuelas-aula. Tal es el caso de la Escuela Modelo madrileña, o de las Escuelas Aguirre de Cuenca y Madrid, inauguradas entre 1885 y $1886 .{ }^{6}$

\section{EL CONCURSO DE MODELOS DE ESCUELAS DE $1869^{7}$}

El sexenio democrático (1868-1874) fue un «período de luces y sombras, de reformas y cambios radicales, pero también de proyectos inacabados, fracasos y rectificaciones». ${ }^{8}$ En este último grupo podrían englobarse las construcciones escolares del sexenio, que, a pesar de las buenas intenciones declaradas en el Decreto-ley de $1869,{ }^{9}$ no consiguieron despegar por falta del necesario respaldo presupuestario. Es necesario, sin embargo, reconocer la importancia de este período en relación con las

\footnotetext{
4 Viñao, «Construcciones y edificios escolares», 494.

5 José María Hernández Díaz, «Espacios escolares, contenidos, manuales y métodos de enseñanza», en Historia de la educación en la España contemporánea. Diez años de investigación, coord. JeanLouis Guereña, Alejandro Tiana y Julio Ruiz (Madrid: Ministerio de Educación Cultura y Deporte, C.I.D.E., 1994), 191-213.

6 Viñao, «La escuela graduada: una nueva organización escolar y pedagógica», 366.

7 Véanse: Viñao, «Construcciones y edificios escolares», 493-534; Francisco Burgos Ruiz, La arquitectura del aula. Nuevas escuelas madrileñas, 1868-1968 (Madrid: Ayuntamiento de Madrid, 2007), 12-18; Francisco Javier Rodríguez Méndez, «Arquitectura escolar en España 1857-1936. Madrid como paradigma» (Tesis doctoral, Universidad Politécnica de Madrid, 2004), 141-59.

8 Viñao, «Construcciones y edificios escolares», 493.

9 Decreto-ley de 18 de enero de 1869, dictando disposiciones para la construcción de Escuelas públicas de Instrucción primaria. Gaceta de Madrid de 23 de enero de 1869, 23, 1-2. https://www.boe.es/ datos/pdfs/BOE/1869/023/A00001-00002.pdf (consultado el 16-5-2020).
} 
construcciones escolares, y fundamentalmente a causa del concurso de proyectos de escuelas que fue convocado como consecuencia del Decreto de 1869. La trascendencia de dicha iniciativa se debe, por un lado, a ser el primer ensayo conocido en España de esta modalidad de selección, sobradamente experimentada por entonces en otras naciones; además, supuso el primer intento de regulación de las condiciones exigibles a los locales escolares, condiciones que quedaron recogidas en el Dictamen de la Comisión encargada de juzgar los proyectos presentados al concurso.

De acuerdo con la convocatoria, el programa mínimo exigible a toda escuela constaba de un local para clase, vivienda del maestro, biblioteca y jardín. La inclusión de la biblioteca dentro de las escuelas respondía a un objetivo cultural prioritario del sexenio como era la creación de las «bibliotecas populares», es decir, bibliotecas al servicio tanto de la comunidad educativa como de la población en general, razón por la cual debían situarse en planta baja y en lugar prominente. ${ }^{10}$

De entre los proyectos presentados a concurso, merecen especial atención los de la Escuela de Arquitectura de Madrid, con cuatro propuestas, y los de Francisco Jareño y Alarcón, conocido arquitecto y profesor de la misma Escuela, con diez proyectos. La Junta de profesores de la Escuela de Arquitectura había designado al profesor de proyectos Manuel Aníbal Álvarez, quien llamó, a su vez, a colaborar con él a sus «antiguos y predilectos alumnos» Emilio Rodríguez Ayuso y Enrique $\mathbf{M}^{\mathrm{a}}$ Repullés y Vargas. ${ }^{11}$ Aunque ambos se titularon en ese mismo año de 1869 , con apenas veinticuatro años, no está del todo claro si en el momento del concurso eran ya arquitectos o no. ${ }^{12}$ Los proyectos así redactados fueron presentados al concurso y fueron seleccionados en primer

\footnotetext{
10 Viñao, «Construcciones y edificios escolares», 494.

11 Artículo «Repullés», Enciclopedia Universal Ilustrada Europeo-Americana, t. 50, 1068-1070 (Madrid: Espasa-Calpe, 1923).

12 Años más tarde, en el obituario de Rodríguez Ayuso, Repullés aclarará que cuando participaron en el concurso ambos eran todavía estudiantes: "pues siendo alumno de ella (de la Escuela de Arquitectura) y en unión del que esto escribe, proyectó, por encargo de la Junta de Profesores y bajo la dirección del de Proyectos, D. Aníbal Álvarez, los de tipos para Escuelas públicas encargados por el Ministerio de Fomento y que obtuvieron el primer premio en el concurso abierto al efecto". [Enrique María Repullés y Vargas, «Obras arquitectónicas de Rodríguez Ayuso», en Biografía y obras arquitectónicas de Emilio Rodríguez Ayuso, ed. Santiago Castellanos y Enrique Ma Repullés (Madrid: Imprenta y litografía de los huérfano, 1892), 17-31, 29].
} 
lugar, lo que valió a la Escuela de Arquitectura una distinción meramente honorífica, ya que no se contemplaba premio en metálico o encargo posterior de ningún tipo.

La experiencia y conocimiento en esta materia de Francisco Jareño -funcionario del Ministerio de Fomento en excedencia y académico de número de la de Bellas Artes, además de catedrático de Escuela de Arquitectura- eran indudablemente muy superiores a las reunidas por Repullés y Rodríguez Ayuso. La Memoria facultativa que acompañaba los proyectos de Jareño, ${ }^{13}$ se basaba en las experiencias llevadas a cabo en la ciudad de Colonia, que el autor conoció de primera mano. En cambio, los noveles arquitectos Repullés y Rodríguez Ayuso recurrieron a la bibliografía disponible en la biblioteca de la Escuela de Arquitectura, y en concreto a la de procedencia francesa.

El juicio de la Comisión sobre los proyectos de la Escuela de Arquitectura -sumamente favorable, claro está- ponía el énfasis en los aspectos positivos e ignoraba totalmente las deficiencias: «La disposición de sus plantas nada deja que desear; la magnitud, forma y conveniente orden en sus dependencias [...] hacen de las proyecciones horizontales o plantas de estos proyectos una verdadera concepción artística». ${ }^{14}$ De la falta de unanimidad en el seno de la Comisión da fe la existencia de un informe anónimo en el que se critican sin paliativos los proyectos de la Escuela de Arquitectura. ${ }^{15}$ La falta de unanimidad y transparencia en el fallo pudo ser una de las causas de la nula difusión que el ministerio de Fomento dio a los proyectos premiados, contraviniendo así lo establecido en las bases del concurso.

\footnotetext{
${ }^{13}$ Francisco Jareño y Alarcón, Memoria facultativa sobre los Proyectos de Escuelas de Instrucción Primaria premiados en concurso público, adquiridos por el Estado y mandados publicar por Decreto de S. A. el Regente del reino de 7 de Abril de 1870. (Madrid: Imprenta del Colegio Nacional de Sordo-mudos y Ciegos, 1871).

${ }_{14}$ Documento $\mathrm{n}^{\circ}$ 4: «Dictamen de la Comisión nombrada por el Excelentísimo Señor Ministro de Fomento, para examinar los proyectos presentados para la construcción de escuelas públicas de primera enseñanza. Gaceta de Madrid de 23 de 15 de febrero de 1870» [Viñao, «Construcciones y edificios escolares», 513].

15 Documento $\mathrm{n}^{\circ}$ 5: «Observaciones sobre las Escuelas primarias presentadas en concurso público. Proyectos de la Escuela» [Viñao, «Construcciones y edificios escolares», 519]. El desconocido autor del informe revela estar en posesión de un profundo conocimiento de la materia que trata. No obstante, ninguna de las sensatas observaciones contenidas en este escrito fueron tenidas en cuenta por la Comisión en su Dictamen.
} 


\section{Los proyectos de la Escuela de Arquitectura de Madrid}

Los cuatro proyectos de la Escuela -los tres tipos exigidos en las bases de la convocatoria más uno adicional- responden a esquemas en planta muy sencillos compuestos en torno a un eje de simetría que se acusa en la fachada principal mediante el avance del cuerpo central. En el eje se suelen disponer la biblioteca y el aula cuando se trata de una sola (tipos 1 y 2). En caso de ser dos, se sitúan a ambos lados del mismo (tipos 3 y adicional), lo mismo que los retretes. En todas las soluciones se percibe una gran influencia de la arquitectura escolar francesa y, más concretamente, de la difundida por la Revue Générale de l'Architecture. De esta publicación están tomadas las ideas básicas sobre organización de la clase y métodos de enseñanza. Los artículos publicados por Paul-Eugène Lequeux entre 1849 y 1851 sobre edificios de instrucción pública ${ }^{16}$ constituyen la base teórica de los modelos proyectados por la Escuela de Arquitectura veinte años más tarde.

El sencillo ropaje formal de las plantas busca manifestar al exterior los procedimientos constructivos empleados. Por medio del uso de dos materiales diferentes (sillería y ladrillo o ladrillo y mampostería) se diferencian claramente los elementos portantes de los de cerramiento.

\section{Primer Tipo. Escuela pública para ambos sexos en población menor de 500 almas}

El edificio se desarrolla en planta baja y adopta una estructura en $\mathrm{H}$, compuesta por dos pabellones -de entrada y de vivienda- enlazados por un tercero, ortogonal a los otros dos, que alberga la clase (figura 1). Este es el único tipo, de los tres presentados por la Escuela de Arquitectura, destinado a los dos sexos, y esto se nota en su disposición absolutamente simétrica. Las dos entradas, situadas a ambos lados de la biblioteca, dan paso a las dos zonas en que se divide el aula por medio de un tabique central que remata contra la mesa del maestro, de modo que, «colocado en su sitio, atiende perfectamente a las dos secciones y estas ni se ven ni pueden comunicarse». ${ }^{17}$

\footnotetext{
16 Paul-Eugène Lequeux, «Édifices pour l'Instruction Publique. Écoles Primaires», Revue Générale de l'Architecture et des travaux publics (1849): 258-61, planchas XXVI-XXVII ; «Édifices pour l'Instruction Publique. Écoles Primaires Communales», Revue Générale de l'Architecture et des travaux publics (1851): 18-28, planchas II-VII.

${ }_{17}$ Enrique María Repullés y Vargas, Disposición, Construcción y Mueblaje de las Escuelas Públicas de Instrucción Primaria (Madrid: Imprenta de Fortanet, 1878), 68.
} 
Tal disposición exige para la clase un ancho excesivamente grande como para cubrirlo de una sola vez (8,5 metros), y por eso se disponen unos pies derechos o columnas centrales que, reduciendo a la mitad el vano, facilitan la construcción.

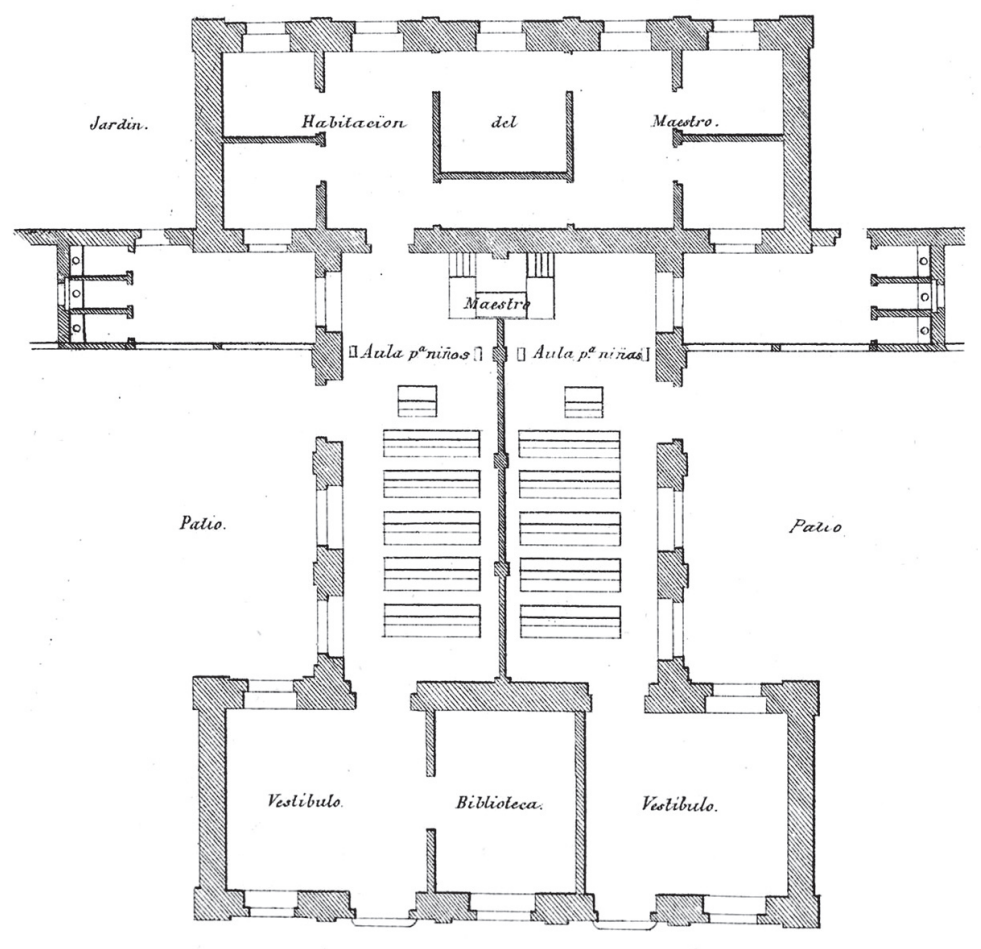

Figura 1. Planta del Primer Tipo presentado por la Escuela de Arquitectura de Madrid al Concurso de 1869 [Repullés, Disposición, Construcción y Mueblaje, Lámina V].

Se trata de una solución novedosa en nuestro país, pero que en Francia venía aplicándose desde bastante tiempo atrás. En una colección de modelos de escuela de 1834, compilados por Bouillon, aparecen varios de este tipo. ${ }^{18}$ La escuela primaria rural mixta proyectada por el arquitecto Lequeux en 1849 presenta igual disposición -explica su autor- por ser el único modo de garantizar la separación entre niñas y niños cuando su instrucción corre a cargo de un solo maestro: «Elle (la classe) devra être divisée en

\footnotetext{
18 Auguste Bouillon, De la construction des maisons d'école primaire (París: Hachette, 1834), 1-2 y plancha 1. Véase también en: Rodríguez, Arquitectura escolar, 149, imagen 21.
} 
deux parties égales par une cloison perpendiculaire à l'entrée, et de 1,40 m de hauteur». ${ }^{19}$ El proyecto de Leculée, premiado en 1863 en un concurso de planos-modelo para escuelas primarias convocado por el ministerio de Instrucción francés, empleaba esta misma disposición. ${ }^{20}$
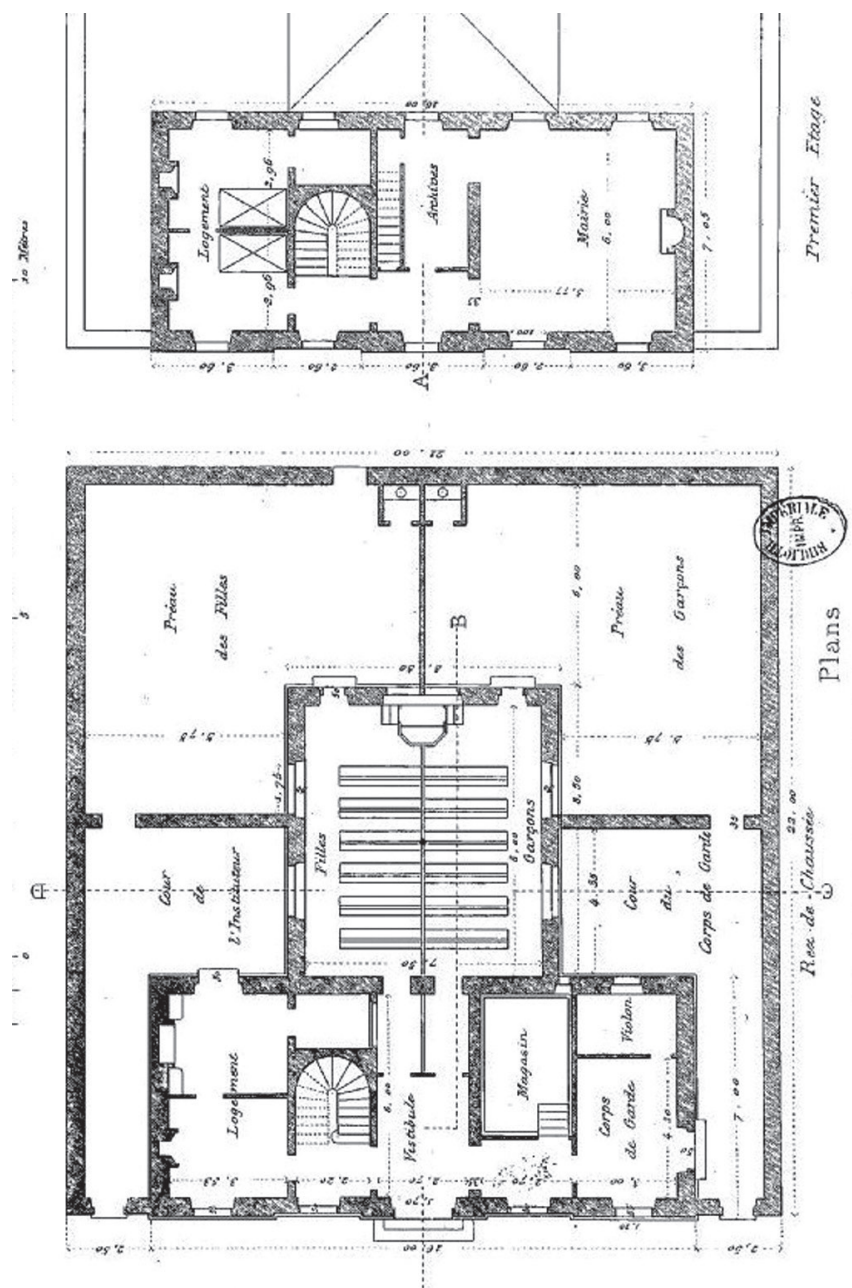

Figura 2. Planta de la Mairie, école mixte et logement d'instituteur en Dammarie-lès-Lys (Francia) [Vacquer, Bâtiments scolaires, Lámina 1].

\footnotetext{
${ }^{19}$ Lequeux, «Édifices pour l'Instruction Publique. Écoles Primaires», plancha XXVI. Véase también en: Rodríguez, Arquitectura escolar, 150, imagen 22.

${ }^{20}$ Châtelet, La naissance de l'architecture scolaire, 56-57. Véase también en: Rodríguez, Arquitectura escolar, 151, imagen 23 .
} 
La mairie-école de Dammarie-lès-Lys (figura 2) posee una gran similitud con el primer tipo de la Escuela de Arquitectura;21 tiene la particularidad de haber sido incluida en una colección de planos-modelo de escuelas publicada seis años antes del concurso,22 que recoge además otros ejemplos concomitantes con proyectos de Repullés y Rodríguez Ayuso, de los que luego se hablará. Por ello, y por encontrarse desde antiguo un ejemplar en la Biblioteca de la Escuela de Arquitectura de Madrid, podría considerarse este libro como posible fuente principal en la que se basaron los arquitectos madrileños.

En su manual sobre las escuelas de Francia e Inglaterra, Félix Narjoux reconoce que el sistema de dividir el aula longitudinalmente mediante un tabique central -sistema exclusivo de Francia según él- le parece algo superfluo dado que, una vez en la calle, los niños y las niñas se mezclarán con total libertad. ${ }^{23}$ En su libro de 1878, también Repullés se distanciará de dicho sistema-adoptado en el primer tipo-, invocando para ello la misma razón que Narjoux. ${ }^{24}$

Pocos ejemplares más de escuelas basadas en este sistema llegarán a erigirse en Francia. Las instrucciones técnicas para la construcción de escuelas, decretadas en 1880, continuarán prescribiendo la separación entre niños y niñas dentro de la clase, pero sin recurrir en lo sucesivo a la interposición de un tabique: «Suppression de la cloison de séparation, groupement des élèves dans les classes des écoles mixtes: La classe de l'école mixte ne sera plus divisée par une cloison séparant les garçons des filles... $»^{25}$

\footnotetext{
${ }^{21}$ En la figura 2 se observa que la planta primera del pabellón principal, destinada a vivienda del maestro, se ha representado aislada y justo por encima de la planta baja de la escuela. Una representación que bien podría haber dado origen a la idea de colocar la vivienda tras el testero del aula y así completar la planta en $\mathrm{H}$ del primer tipo.

${ }_{22}$ Théodore Vacquer, Bâtiments scolaires récemment construits en France et propres à servir de types pour les édifices de ce genre (París: Caudrilier, 1863), 9 y lámina 1.

${ }^{23}$ Félix Narjoux, Les Écoles Publiques en France et en Angleterre. Construction et installation (París: A. Morel et Cie., 1877), 138-39.

${ }^{24}$ Repullés, Disposición, Construcción y Mueblaje, 26.

${ }_{25}$ Artículo 32 del Règlement pour la construction et l'ameublement des maisons d'école, decreto de 17 de junio de 1880. Su redacción corrió a cargo de una comisión multidisciplinar-el Conseil supérieur de l'Instruction publique-, creada en los primeros meses del ministerio de Ferry, en la que figuraban los arquitectos Viollet-le-Duc, Narjoux, Trélat, Vaudremer y Salleron [Châtelet, La naissance de l'architecture scolaire, 80-6].
} 
Segundo Tipo. Escuela pública para un solo sexo en población de 500 a 5.000 almas

Su planta adopta la forma de una cruz latina en la que clase y biblioteca se sitúan en el brazo mayor, que se manifiesta en la fachada por medio del saliente de la biblioteca (figura 3). Los otros dos brazos, simétricos respecto al eje, alojan los dos vestíbulos, uno para la clase y el otro -más pequeño- para la biblioteca y la escalera que conduce a la vivienda del maestro en la planta primera.

El parentesco con la mairie-école de Dammarie-lès-Lys (figura 2) es ahora, quizás, mayor que en el primer tipo, y más aún si se suprime el tabique central y se estrecha el ancho de la clase. Entre las escuelas francesas construidas en el siglo XIX, ${ }^{26}$ las que poseen planta en T son casi tan numerosas como las de esquema ternario -, es decir, con cuerpo central de dos plantas y dos alas laterales más bajas con las clases -, a las que nos referiremos más adelante.

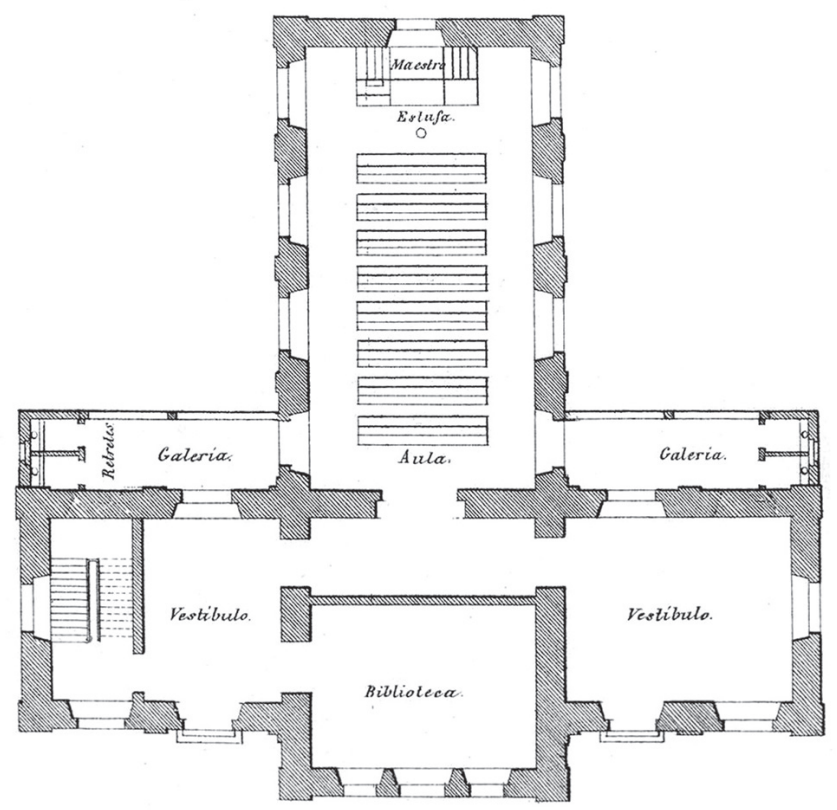

Figura 3. Planta del Segundo Tipo presentado por la Escuela de Arquitectura de Madrid al Concurso de 1869 [Repullés, Disposición, Construcción y Mueblaje, Lámina VI].

${ }^{26}$ Christine Granier y Jean-Claude Marquis, «Une enquête en cours: La maison d'école au XIXe siècle», Histoire de l'éducation 17 (1982): 31-46, 36. 
La clase mide 12 x 6,5 metros. Esta superficie es más proporcionada que la del primer tipo, pues tiene aproximadamente el doble de largo que de ancho. Aún así, el ancho es insuficiente si, tal como dice Repullés, se van a utilizar los pasillos laterales para la enseñanza en secciones. Es interesante contrastar el criterio de Repullés, en lo tocante al empleo del sistema de enseñanza, con el de Jareño, expresado en 1869, que no era otro que el que en adelante sería habitual:

Conviene advertir que la rutina o mala inteligencia ha introducido en algunas escuelas de Francia y aún de España, las tarimas colocadas a cierta distancia entre sí, arrimadas a las paredes, para la reunión de las secciones o grupos de niños en semicírculos. Estos entorpecimientos en los pasos de la sala quitan un grande espacio que debe ocuparse con mesas, exponen a los niños a continuos sobresaltos y caídas por la propensión a empujarse mutuamente y, por tanto, debe desecharse y prohibirse práctica tan defectuosa. Además el método de enseñanza en el cual son indispensables los semicírculos, ofrece grandes inconvenientes y tiende a desterrarse en todas partes. ${ }^{27}$

Al igual que en el resto de los tipos, la iluminación de la clase es bilateral, criterio muy discutido ya en ese momento y del que prescindirá en adelante por ser perjudicial para la vista de los escolares. El aspecto de la clase tipo empleada en los proyectos de la Escuela de Arquitectura puede apreciarse en el grabado que Repullés reproduce en su libro (figura 4).

${ }_{27}$ Jareño, Memoria facultativa, 79. 


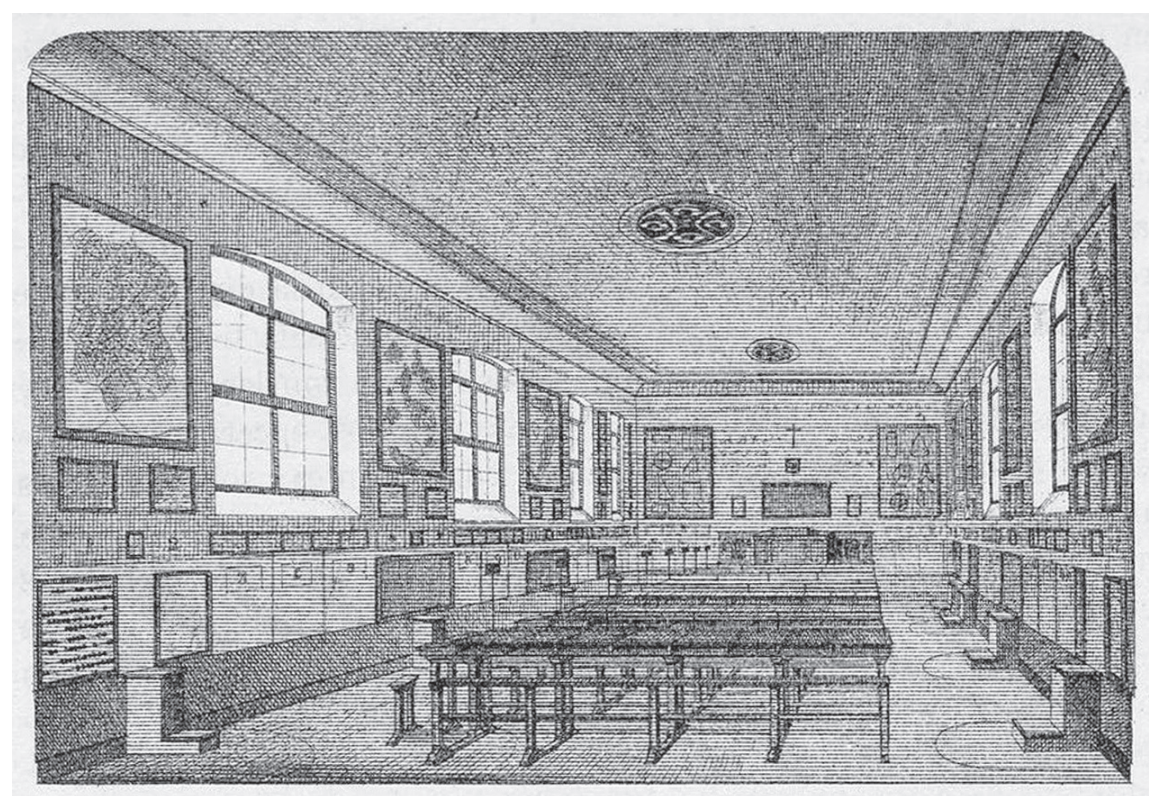

Figura 4. Vista de la clase propuesta por la Escuela de Arquitectura de Madrid en el Concurso de 1869 [Repullés, Disposición, Construcción y Mueblaje, Lámina IV].

Tercer Tipo. Escuela pública para un solo sexo en población mayor de 5.000 almas

El edificio proyectado se compone de dos pabellones que, en planta, presentan como en el caso anterior una tipología en T (figura 5), en la que las posiciones de la vivienda y de la clase están permutadas. En planta baja, la clase, de 26 metros de longitud por 6 de anchura, se desarrolla en paralelo a la calle de acceso. El vestíbulo y la escalera de subida al segundo nivel componen, junto con los pasos al aula, un segundo pabellón ortogonal al primero que avanza al encuentro de la calle y cuyo eje de simetría coincide con el del aula. En el segundo piso se sitúan la biblioteca -sobre el vestíbulo de entrada-, un aula complementaria y la vivienda del maestro. Estos dos espacios se reparten entre ambos los 26 metros de longitud del pabellón longitudinal que ocupa la clase en planta baja.

De todos los proyectos presentados por la Escuela de Arquitectura este es, sin duda, el más deficiente. Sus defectos más notables, que harían imposible su aplicación práctica, se refieren a la clase y son denunciados en el anónimo informe, ya mencionado: «La disposición de la sala no puede 
ser más defectuosa. Si el maestro ha de vigilar a los escolares que se encuentran a su derecha e izquierda, su cabeza debe estar en continuo movimiento.... ${ }^{28}$ Su desconocido autor critica además, por un lado, la exagerada desproporción entre anchura y longitud del aula y, por otro, la superabundante profusión de ventanas repartidas por los cuatro lados del apaisado rectángulo. Conscientes del primero de los dos problemas mencionados, los autores del proyecto tratan de minimizar las dificultades inherentes a una longitud tan desmesurada colocando al maestro en el punto medio del muro que separa de la galería, pero obligándolo a volver la cabeza constantemente a uno y otro lado para vigilar desde su sitio.

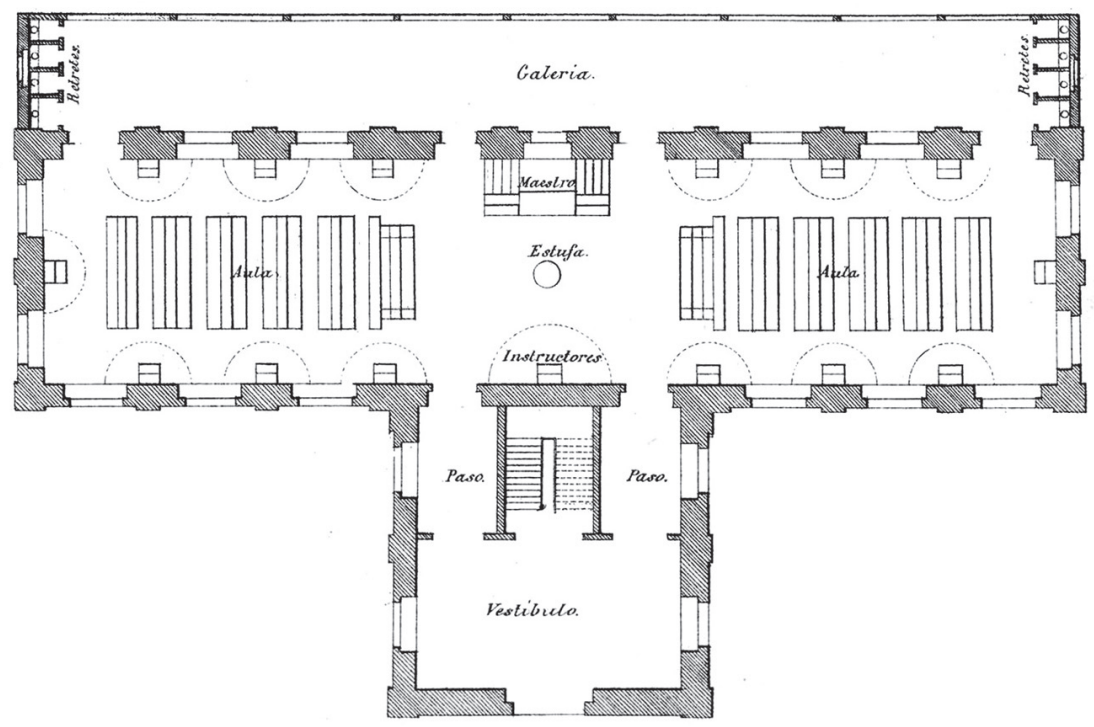

Figura 5. Planta del Tercer Tipo presentado por la Escuela de Arquitectura de Madrid al Concurso de 1869 [Repullés, Disposición, Construcción y Mueblaje, Lámina VII].

Tipo adicional. Escuela para los dos sexos en poblaciones de 500 a 5.000 almas

Una localidad de tal importancia justifica la dotación de dos maestros, razón por la cual esta escuela consta de dos clases separadas -una para niños y otra para niñas- y de dos viviendas, además de la biblioteca. Dicho programa se encaja en un edificio de una sola planta distribuido en T (figura 6), en el que las clases ocupan los extremos del brazo paralelo a la calle

28 Documento $n^{\circ} 5$ [Viñao, «Construcciones y edificios escolares», 522]. 
y las viviendas los del brazo perpendicular, todo ello según un esquema rigurosamente simétrico. El brazo perpendicular o central actúa como barrera de separación entre los patios de recreo y se manifiesta en fachada por un pequeño saliente que esconde detrás la biblioteca. A ambos lados de la misma, los vestíbulos correspondientes a uno y otro sexo dan paso a la clase respectiva y a la vivienda de su maestro asignado. Las dimensiones más regulares de las clases ( 11 x 5,6 m) las hacen aptas para un solo grupo de 60 alumnos y un sistema simultáneo de enseñanza. Las características enumeradas hacen de este pequeño grupo escolar un tipo más aceptable que los tres anteriores, aun siendo el «adicional».

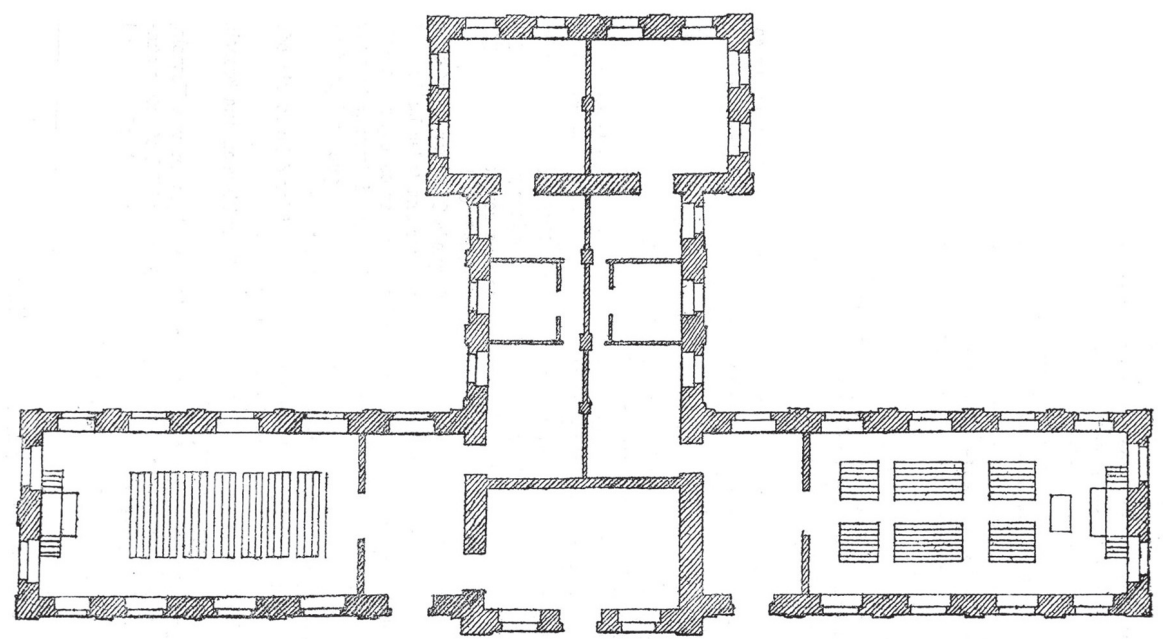

Figura 6. Planta del Tipo Adicional presentado por la Escuela de Arquitectura de Madrid al Concurso de 1869 [Repullés, Disposición, Construcción y Mueblaje, 72].

Las escuelas francesas de planta en T construidas en Francia durante el siglo XIX constituyen un caso particular de las de esquema ternario, es decir, aquellas de tres cuerpos con uno central de dos plantas -destinadas normalmente a ayuntamiento la inferior y a viviendas la superior- y dos alas laterales simétricas de una sola planta con las clases. ${ }^{29}$ Según la clasificación de Granier y Marquis, en una escuela francesa de esquema en $\mathrm{T}$ las clases

\footnotetext{
29 De entre los abundantes ejemplos de mairie-école construidos en Francia durante el Segundo y Tercer Imperio, véanse algunos en: Parc naturel régional de la Haute Vallée de Chevreuse. https://www. parc-naturel-chevreuse.fr/park-protected-area/un-territoire-preserve-patrimoine-historique/mairies-ecoles (consultado el 22-5-2020).
} 
podían ocupar el pie de la T, como en el segundo tipo de la Escuela de Arquitectura, o los brazos de la T, como en el tercer tipo o en el adicional. En este segundo caso, el cuerpo central o pie de la $\mathrm{T}$ se destinaba a diversas funciones como vivienda o biblioteca, e incluso a telégrafo o sala de actos. ${ }^{30}$

En la colección de modelos de escuela compilados por Bouillon en 1834, aparece uno de este tipo (figura 7), destinado a 160 niños de ambos sexos, ${ }^{31}$ en el que los brazos de la T alojan en planta baja las clases y en planta alta las viviendas, siendo precedidos dichos brazos por el cuerpo central destinado a los préaux couverts ${ }^{32}$ correspondientes a cada clase.

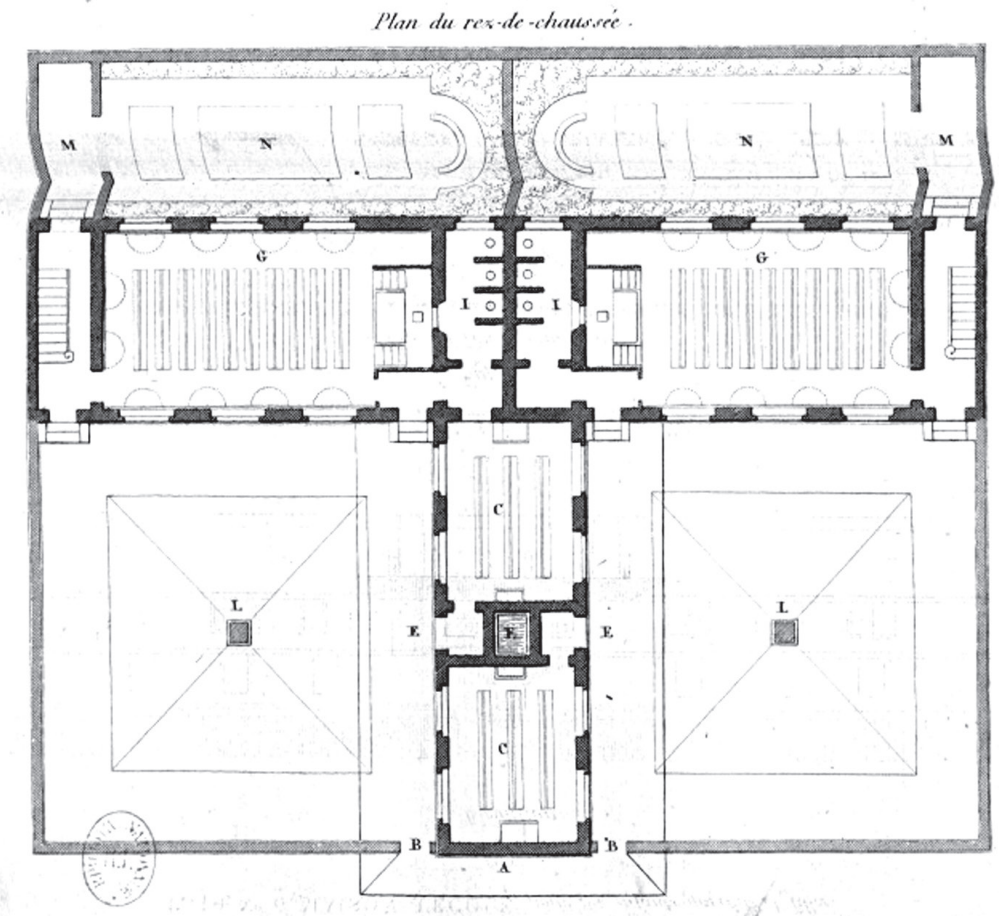

Figura 7. Planta de la escuela para 160 alumnos, niños y niñas [Bouillon, De la construction des maisons d'école primaire, plancha 3].

\footnotetext{
30 Granier y Marquis, «Une enquête en cours», 36.

31 Bouillon, De la construction des maisons d'école primaire, 27 y plancha 3.

32 «La dependencia llamada por los franceses patio cubierto (préau couvert), y que también podemos denominar salón de recreo, es una gran pieza destinada, no solo al esparcimiento de los niños, cuando el temporal no les permite tenerle al aire libre, sino también a hacer oficios de vestíbulo, guarda-ropa, sala de aseo y refectorio». [Repullés, Disposición, Construcción y Mueblaje, 15-16].
} 


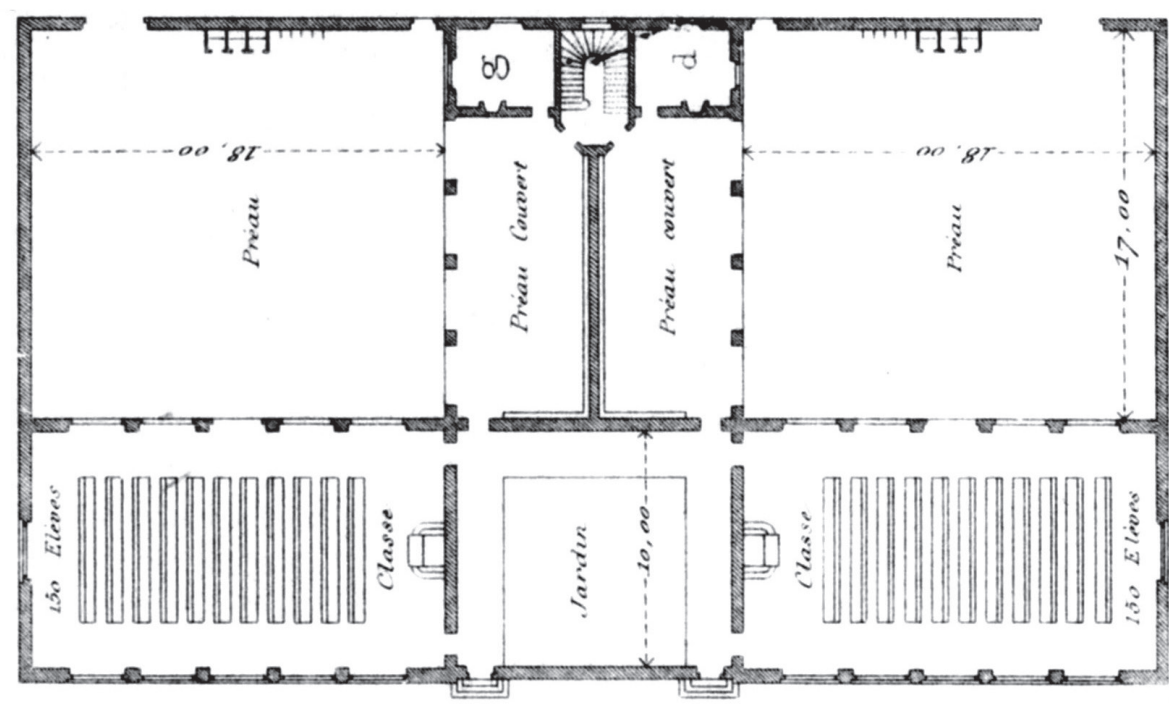

Figura 8. Planta de la escuela del barrio Petit-Monrouge (París)

[Vacquer, Bâtiments scolaires, Lámina 3].

La escuela del barrio parisino de Petit-Monrouge, incluida en la colección de escuelas publicada por Vacquer en 1863,33 presenta una disposición muy similar, con la salvedad de situar las viviendas sobre los préaux couverts del pie de la $\mathrm{T}$ y no sobre las clases, como en el caso anterior (figura 8). Vacquer pone de relieve esta escuela incluyéndola en su colección, pero no por ello se priva de plantear alguna mejora relativa a los defectos que en ella detecta. Entiende el autor que los préaux couverts deberían estar cerrados por medio de ventanas y poseer una mayor extensión. Para resolver esta última cuestión, propone Vacquer prolongar los préaux hasta la línea de fachada de las clases, a costa de un jardín delantero carente para él de utilidad. Como en el caso del primer tipo, de nuevo nos parece que el modelo que más pudo influir en el presente tipo es un modelo incluido en el libro de Vacquer (figura 8). Caso de haber sido así, de nuevo Repullés y Rodríguez Ayuso emplearon aquí el recurso de llevar las viviendas a la planta baja, ahora en sustitución de los préaux couverts, y, siguiendo el consejo de Vacquer, prolongan el brazo central por medio de la biblioteca hasta la fachada exterior de las clases.

33 Vacquer, Bâtiments scolaires récemment construits, 11 y lámina 3. 

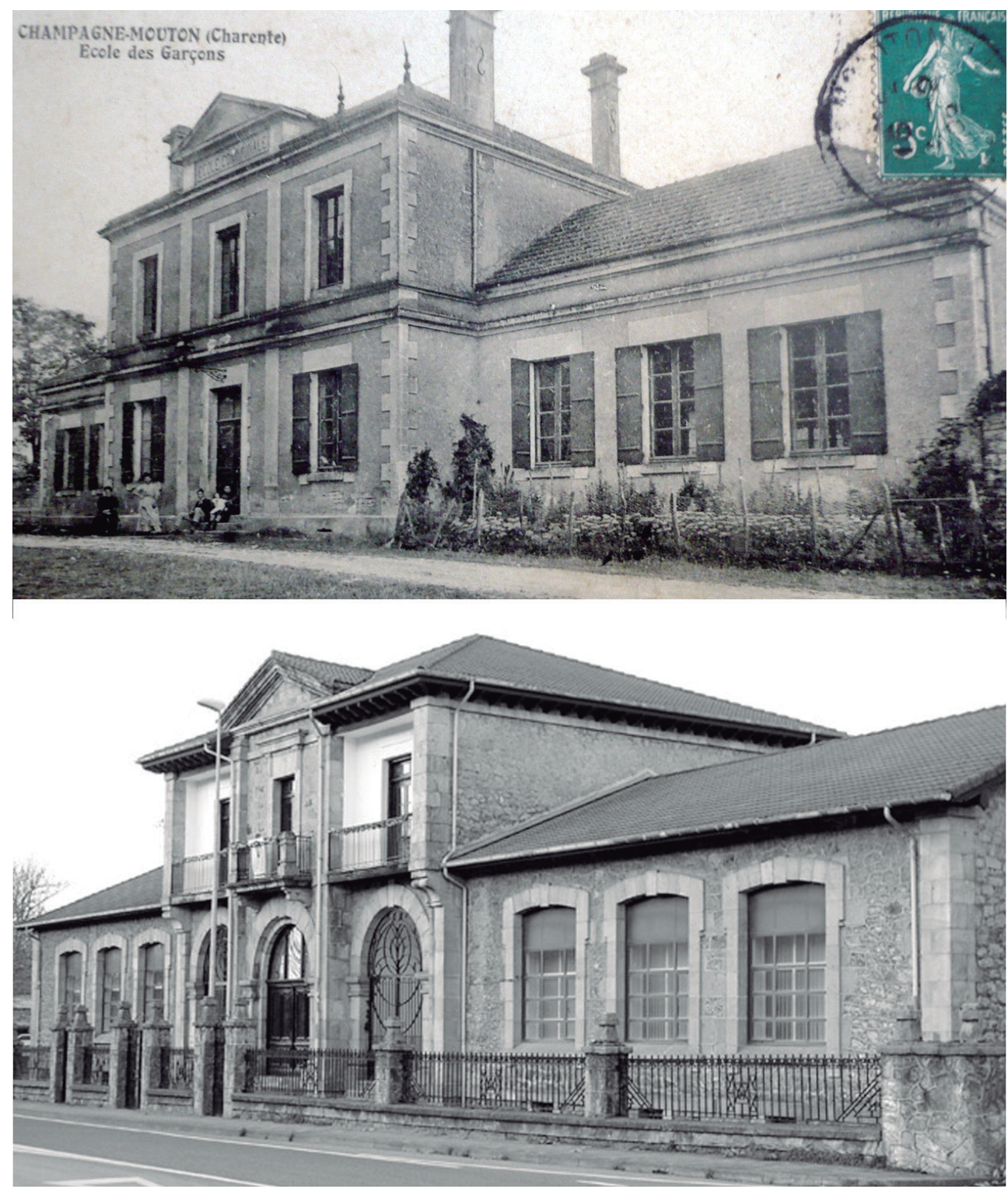

Figura 9. Arriba: Escuela de Champagne-Mouton (Francia). 1882-1885. Abajo: Escuela de Pámanes (Cantabria). 1906-1909. Arq.: Valentín Ramón Lavín Casalís.

En su libro de 1878, al referirse a las escuelas que su compañero Rodríguez Ayuso había proyectado recientemente en Cuenca, Repullés sostiene que aquel lo hizo basándose en el «tipo adicional de los proyectos 
formados por la Escuela de Arquitectura».34 Sin embargo, nos parece más bien que ambos esquemas son herederos de un tercero importado de Francia: la mairie-école, tan profusamente utilizada en el país vecino, especialmente a partir de la Tercera República. La variante española incorpora viviendas de maestros en lugar de locales municipales y pervivirá con buena salud en todo el ámbito nacional hasta bien entrado el siglo XX. ${ }^{35} \mathrm{Su}$ tipología es lineal, simétrica y tripartita, con un cuerpo central de dos plantas -la superior destinada a las viviendas- $\mathrm{y}$ alas laterales destinadas a clases. La relación de parentesco se percibe claramente si se confrontan ejemplares de escuela de uno y otro lado de los pirineos; por ejemplo, la escuela de Champagne-Mouton (Francia), construida entre 1882 y 1885, y la de Pámanes (Cantabria), entre 1906 y 1909 (figura 9).

La consideración del tipo adicional como prototipo germinal en la arquitectura escolar española posterior ha gozado de considerable predicamento entre los estudiosos de la materia. Llano Díaz, por ejemplo, afirma refiriéndose a Cantabria que el tipo adicional «inspiraría gran parte de las construcciones escolares más importantes a partir de los años 80 del XIX, difundiéndose por toda la región». ${ }^{36}$ Dicho autor identifica numerosos edificios escolares cántabros basados en el tipo adicional que fueron proyectados por arquitectos de renombre tales como Alfredo de la Escalera, Valentín Ramón Lavín, ${ }^{37}$ Joaquín Rucoba, Gonzalo Bringas o Emilio de la Torriente. Nos parece algo forzada la atribución de tal influjo a la sencilla planta de un edificio que no llegó a ser construido jamás. Y ello con mayor motivo si se tiene en cuenta que en las bibliotecas de nuestras Escuelas de Arquitectura abundaban las publicaciones extranjeras, plenas de vistosas ilustraciones de edificios escolares construidos según esquemas similares.

\footnotetext{
${ }^{34}$ Repullés, Disposición, Construcción y Mueblaje, 78.

35 Anne-Marie Châtelet establece un parentesco similar entre la mairie-école francesa y las escuelas confesionales alemanas [Anne-Marie Châtelet, «Dialogue France-Allemagne sur l'architecture et la pédagogie», Proyecto Progreso Arquitectura 17 (2017): 16-27].

36 Ángel Llano Díaz, «Notas sobre el espacio rural escolar en Cantabria (1850-1936)» [en línea], Cabás: Revista del Centro de Recursos, Interpretación y Estudios en materia educativa (CRIEME) de la Consejería de Educación del Gobierno de Cantabria (España) [publicación seriada en línea] 1 (2009). http://revista.muesca.es/articulos/66-notas-sobre-el-espacio-rural-en-cantabria-1850-1936 (consultado el 26 de mayo de 2020).

37 Entre las escuelas proyectadas por Valentín R. Lavín en Cantabria, que Llano Díaz estima basadas en el tipo adicional, está las de Pámanes, representada en la parte inferior de la figura 9 [Llano, «Notas sobre el espacio rural escolar en Cantabria», 12-3].
} 


\section{Los proyectos de Francisco Jareño}

Francisco Jareño, Catedrático de la Escuela de Arquitectura de Madrid, no logró ser designado como su representante en el concurso de modelos de 1869. A pesar de ser muy superiores sus méritos a los del equipo elegido, se vio obligado a presentarse al certamen a título particular. Jareño afirma en la introducción de la Memoria facultativa que acompañaba sus proyectos que, "al observar cómo se atiende a este ramo en las naciones cultas», ${ }^{38}$ él mismo decidió emprender un estudio análogo sobre construcciones escolares, y que se hallaba precisamente realizando esa labor cuando se anunció la convocatoria del concurso. Más adelante, el autor manifiesta haber visitado la Exposición universal de París de 1867, deteniéndose especialmente en los avances en materia de organización escolar de países tales como Inglaterra, Francia, Bélgica, Sajonia, Baviera y Prusia. Ello le llevó a visitar personalmente, "para examinarlos de cerca en todas sus particularidades y detalles», los principales establecimientos escolares de Sajonia y Prusia por ser estos los que revestían, a su juicio, «el mayor grado de perfección». La organización y sistemas de enseñanza de estos dos países, así como la disposición de los edificios y mobiliario de sus escuelas, sirvieron de base a Jareño en la redacción de su trabajo.

La Memoria se divide en tres partes: la primera contiene algunas consideraciones sobre la organización de la enseñanza en Sajonia y Prusia; la segunda describe los edificios de escuela visitados en estos dos países; la tercera, basada en las dos anteriores, comprende los modelos presentados por Jareño al concurso.

De los diez proyectos presentados por Jareño al concurso, solo dos -los señalados con los números 8 y 10 - fueron considerados como adoptables por la comisión evaluadora. El resto fueron desechados por no cumplir con las bases, en especial con la necesidad de incluir la biblioteca. Jareño era consciente de esto, y así lo menciona en su Memoria facultativa, pero justifica la presentación de la totalidad de los tipos por ser todos ellos muy recomendables para las pequeñas poblaciones por su economía:

El Jurado, ateniéndose a las condiciones del concurso, admite únicamente los proyectos que las cumplen. En su rectitud no podía proceder de otro modo; pero es menester decir sin rebozo que

\footnotetext{
38 Jareño, Memoria facultativa, 5-7.
} 
por aspirar a la perfección se renuncia a lo practicable y hacedero, a lo que se acomoda mejor a las circunstancias especiales de la mayoría de los pueblos de España, en cuyo caso se hallan los proyectos números 1 al 7 de esta Memoria, tanto por su coste como por las demás condiciones. ${ }^{39}$

No es posible consultar los planos de las escuelas proyectadas por Jareño. ${ }^{40}$ En su libro, publicado un año después del fallo, se representa únicamente la planta de una clase aislada del resto del edificio en que se integra (figura 10). Dicha clase es como las de las escuelas de Colonia, que dio a conocer en la primera parte del texto. Sus dimensiones son las que más adelante se considerarán canónicas: 20 por 30 pies o, lo que es lo mismo, 6,28 por 9,42 metros. La organización de la clase es también la que en adelante será habitual para el tipo de enseñanza simultánea: dos filas de pupitres separadas de las paredes laterales por pasillos y entre ambas por un pasillo central cuyo eje coincide con la mesa del maestro. La iluminación es del tipo unilateral izquierda. En resumen, se trata de una clase adaptada a los últimos avances pedagógicos.

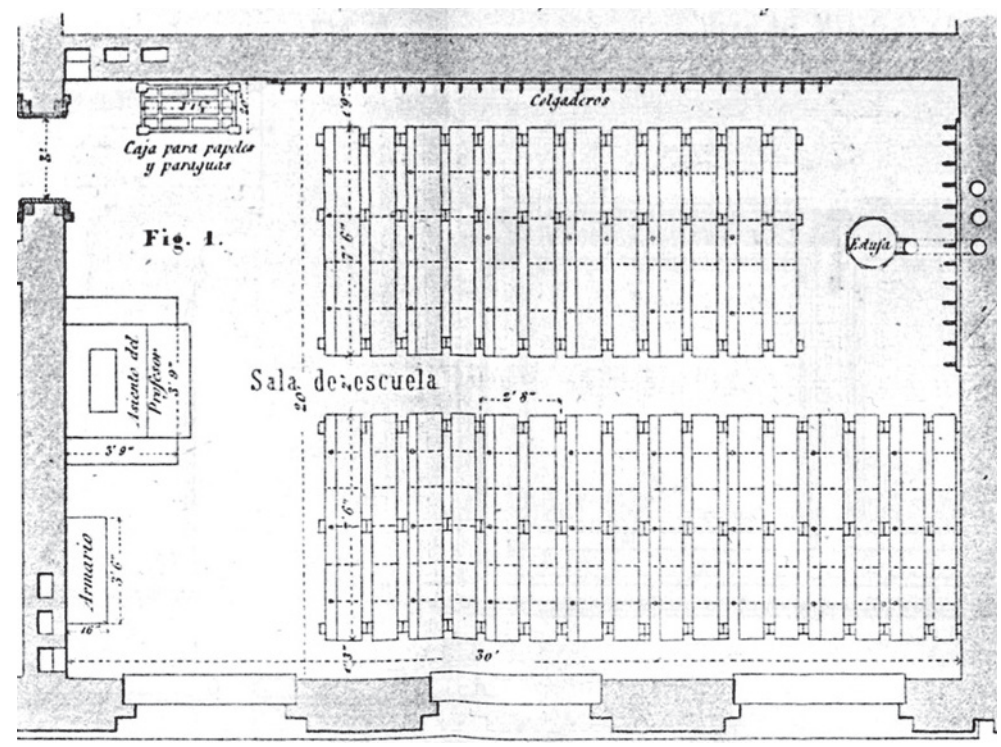

Figura 10. Sala de Escuela presentada al Concurso de 1869 [Jareño, Memoria facultativa, Lámina II].

\footnotetext{
39 Jareño, Memoria facultativa, 83.

40 Viñao, «Construcciones y edificios escolares», 499, nota 13.
} 
De acuerdo con la descripción escrita, los modelos propuestos por Jareño iban del más sencillo posible -formado por la sala de clase y un pórtico abierto a ella adosado-, a los más complejos de dos pisos y espacios complementarios tales como la biblioteca o la vivienda del maestro. En alguno de los modelos se agrupan dos o más salas de clase, lo cual los hace idóneos para las grandes ciudades donde no se dispone de solares espaciosos. El modelo número 8, valga como ejemplo, consta de dos cuerpos bien diferenciados: el principal albergando cuatro espacios similares al descrito más arriba (figura 10), de los cuales dos son clases y los dos restantes biblioteca y gimnasio; el cuerpo secundario se destina a vivienda del maestro. A diferencia de lo que ocurre en los proyectos de la Escuela de Arquitectura, donde los usos se solapan, Jareño independiza totalmente las entradas de escuela y vivienda, si bien «el maestro puede comunicarse por el interior de sus habitaciones con las salas de escuela».41

La Comisión se sorprende del hecho de que en los proyectos 8 y 10 -los únicos aceptados- «el jardín esté comprendido dentro del perímetro general del edificio, y de que dos de sus lados sean cerramientos o medianerías con otros edificios contiguos».42 Aunque se carezca de plantas generales, la clase de la figura 10 muestra en su ángulo inferior derecho el modo en que la fachada se prolonga más allá del edificio. Ello induce a pensar que la disposición de los modelos de Jareño, que la Comisión objetaba, debía ser similar a la que presentan los modelos franceses mostrados más arriba (figuras 2, 7 y 8), o a la de los modelos publicados por el ministerio de Instrucción pública y Bellas Artes en 1908;43 en resumen, modelos que por estar rodeados de tapias poseen un cierto carácter introvertido.

Francisco Jareño presentó también a concurso un proyecto adicional que, en su caso, comprendía dos escuelas a construir en la huerta de la Escuela Normal Central. Por no ser requerido en las Bases del concurso, dicho proyecto no fue tenido en consideración. ${ }^{44}$ Algunos años después,

\footnotetext{
41 Jareño, Memoria facultativa, 74.

42 Documento no 4 [Viñao, «Construcciones y edificios escolares», 514].

43 Elena de Ortueta Hilberath, «Los modelos de escuelas destinados a los centros de educación primaria pública avalados por el Negociado de Arquitectura Escolar del Ministerio de Instrucción Pública y Bellas Artes», Norba: Revista de arte 17 (1997): 165-92, 187-88.
}

44 Documento n 4 [Viñao, «Construcciones y edificios escolares», 517]. 
Jareño proyectó para este mismo lugar el edificio escolar denominado Jardines de la Infancia, que no era, evidentemente, el presentado al concurso de 1869 y que se estudiará más adelante.

Una aportación de gran interés de la Memoria facultativa fue la difusión que dio su autor a una escuela construida pocos años antes en la ciudad de Washington, que tendría -ya en el siglo XX- una curiosa secuela en nuestro país. Pero dejemos que sea el propio Jareño quien describa este edificio que tanto le fascinó (figura 11): "Tiene todo el carácter de las modernas construcciones alemanas. Su conjunto es bello y armonioso, rico en detalles y de una ejecución esmerada. Está construido con fábricas de ladrillo fino al descubierto, y su distribución es regular y simétrica para niños y niñas». ${ }^{45}$ La tipología del edificio, compacta y simétrica, posee evidentes ventajas en orden a la economía de la construcción y a la facilidad del control, pero, por otro lado, es causa de la deficiente orientación de la mitad de las clases y de la iluminación unilateral derecha con que cuentan algunas de ellas. Repullés también mencionará en su libro estas escuelas de Washington (también sin citar la fuente). Las incluirá entre las escuelas extranjeras dignas de estudio, pero las descartará como modelo para las españolas, pues «sólo podrán ofrecernos algún detalle aprovechable, pero pocas veces o nunca un conjunto que satisfaga a nuestras necesidades».46

Aunque Jareño no aportaba más datos sobre la escuela en cuestión, una investigación reciente ha establecido que se trata de la Wallach School, proyectada por el arquitecto americano de origen alemán Adolf Cluss, inaugurada en la ciudad de Washington en 1864 y derribada en $1950 .{ }^{47}$ Francisco Jareño, mientras preparaba su participación en el concurso de modelos de escuelas de 1869, tuvo conocimiento de la escuela Wallach mediante el artículo publicado ese mismo año en Allgemeine Bauzeitung, ${ }^{48}$ e incluyó sus planos en la Memoria facultativa.

\footnotetext{
45 Jareño, Memoria facultativa, 78-9.

${ }^{46}$ Repullés, Disposición, Construcción y Mueblaje, 84.

${ }^{47}$ Francisco Javier Rodríguez Méndez, «La huella de Adolf Cluss en la escuela graduada de Cartagena», Foro de Educación 12 (2014): 69-89.

48 Adolf Kluss y J. W. Kammenhüber, «Schulgebäude zu Washington», Allgemeine Bauzeitung mit Abbildungen (1868-69): 34-35 y 186-188). Consultado el ejemplar conservado en la biblioteca de la Escuela de Arquitectura de Madrid, se constata que faltan en él las páginas 34 y 35 con las ilustraciones del artículo.
} 


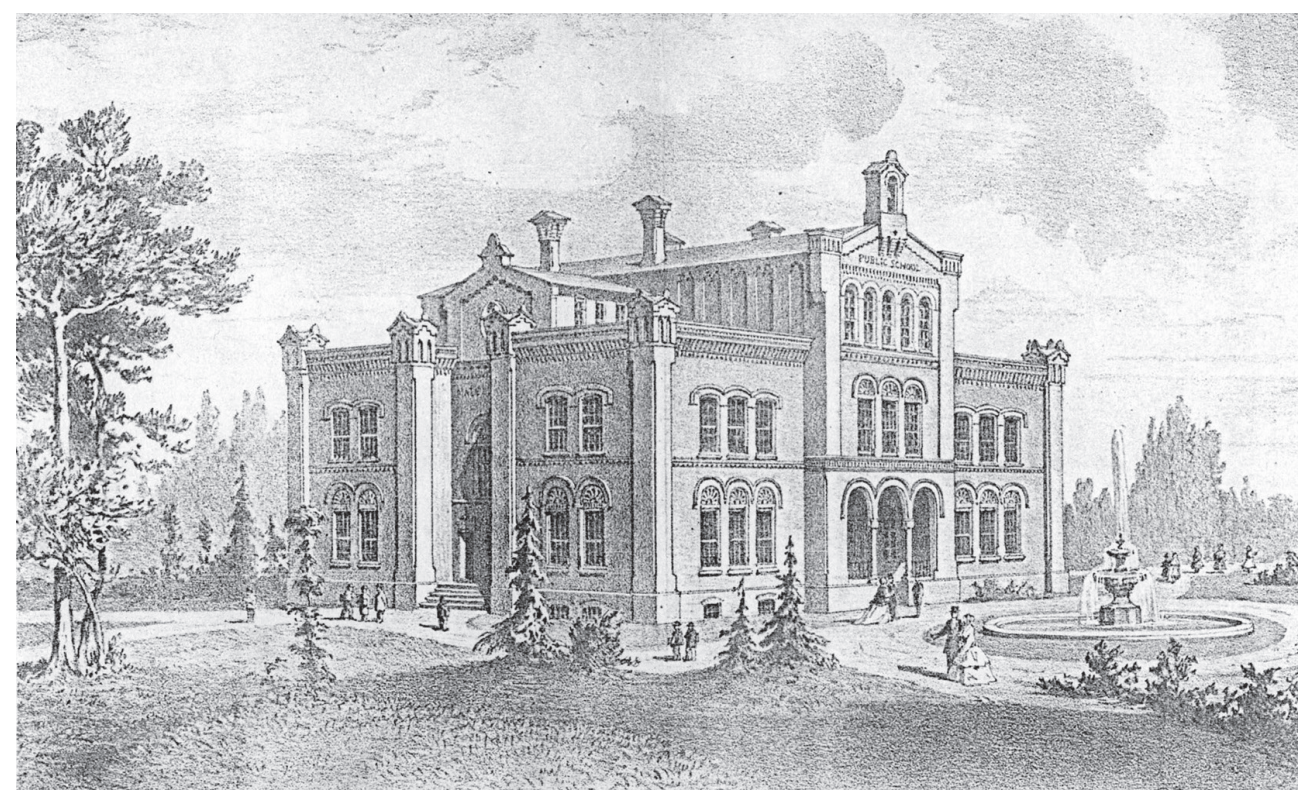

Figura 11. Edifico de Escuela en Washington [Jareño, Memoria facultativa, Lámina VI].

El edificio de la escuela graduada de Cartagena ${ }^{49}$-primera que en España se construyó específicamente para tal fin- tiene su origen en la Wallach School. El parentesco entre la escuela de Cartagena y una de Washington era conocido desde los tiempos de su gestación. Martínez Muñoz, quien sería su primer director junto con Félix Martí Alpera, había propuesto unos años antes de la construcción un edificio «diseñado a partir de una escuela de Washington».50 Probablemente fue Martí Alpera, buen conocedor de la bibliografía sobre construcciones escolares, quien facilitó el modelo a copiar al arquitecto Tomás Rico mientras este proyectaba la escuela de Cartagena.

\section{«Disposición, Construcción y Mueblaje...», de Repullés y Vargas}

A diferencia de Jareño, quien en su libro se limitó a divulgar la memoria de los proyectos presentados a concurso un año antes, Repullés

\footnotetext{
49 Véase: Félix Martí Alpera, Por las escuelas de Europa (Valencia: Imprenta Vives, 1904), 355-60.

50 Antonio Viñao Frago, Innovación pedagógica y racionalidad científica. La escuela graduada pública en España (1898-1936) [Madrid: Akal, 1990], 17.
} 
esperó casi diez para completar y dar a la prensa el suyo. El libro de Repullés, publicado en Madrid en 1878, era la segunda edición de su trabajo; la primera se había dado a conocer por entregas en trece números sucesivos de la revista Anales de la Construcción y de la Industria, a caballo entre los años 1877 y $1878 . .^{51}$ En el libro se mostraban los planos presentados al concurso, acompañados de una, en principio, novedosa memoria de considerable extensión.

Para la redacción del libro se consultaron «los autores que más se han ocupado del asunto, aceptando opiniones de unos y otros según los casos». ${ }^{52}$ A lo largo de la obra va Repullés desvelando los nombres de esos autores. Reconoce la influencia de Narjoux, de cuya obra sobre las escuelas de Francia e Inglaterra afirma «somos deudores en algunos datos». ${ }^{53}$ Más que eso, sostenemos nosotros, lo que hizo en un gran porcentaje de la obra fue traducir sin citar la fuente. ${ }^{54}$ Un análisis exhaustivo de los párrafos que Repullés dedica a los distintos elementos de la escuela (puertas, ventanas, piso, techos, muros, división de las clases, clases de dibujo, talleres, patios de recreo, etc.) demuestra que, en gran medida, la obra del arquitecto español es una traducción del libro de Narjoux sobre las escuelas francesas e inglesas, en la que ha introducido las modificaciones puntuales que le ha parecido conveniente. A modo de ejemplo, se confronta a continuación un texto de Repullés referido a los patios de recreo con su correspondiente fuente en el libro de Narjoux:

Sobre si han de plantarse árboles en ellos [los patios de recreo] se ha discutido mucho, pero es claro que esto depende del clima y condiciones de cada país. En unas partes serán convenientes para evitar los rayos solares, y en otras habrá que proscribirlos como

\footnotetext{
${ }^{51}$ Enrique María Repullés y Vargas, «Nuevas escuelas de instrucción primaria en Cuenca», Anales de la construcción y de la industria II (1877): 88-90.

- «Edificios destinados a escuelas públicas de instrucción primaria». Anales de la construcción y de la industria II (1877): 212-5, 234-6, 246-9, 290-5, 310-3, 321-5, 340-2 y 358-1.

- «Edificios destinados a escuelas de instrucción primaria». Anales de la construcción y de la industria III (1878): 1-4, 21-6, 53-5, 86-9 y 145-7.

${ }^{52}$ Repullés, Disposición, Construcción y Mueblaje, V.

${ }_{53}$ Repullés, Disposición, Construcción y Mueblaje, 47.

${ }_{54}$ Véase un estudio pormenorizado de esta cuestión en: Francisco Javier Rodríguez Méndez, «Influencia francesa en la arquitectura escolar española», en Francia en la educación de la España contemporánea (1808-2008), ed. José Mª Hernández (Salamanca: Universidad de Salamanca, 2011), 185218.
} 
productores de humedad.= En Inglaterra se ha hecho cuestión muy importante la de los patios de las escuelas, siendo elemento indispensable del sistema de educación; por eso cuidan tanto de orientarlos al Sur o al Este, nunca al Norte u Oeste [...].55

La question de savoir si la cour de récréation (préau découvert) d'une école doit rester nue ou être plantée d'arbres a souvent été débattue; c'est là une question de climat. Dans le Midi, en Provence par exemple, les arbres son non-seulement utiles, mais indispensables; dans le Nord, au contraire, ils peuvent être une cause d'humidité et, par suite, devenir nuisibles [...] Les Anglais attachent une très grande importance à la cour de récréation (play ground) de leurs écoles, à ses dimensions et ses dispositions; elle constitue pour eux un des éléments essentiels, nécessaires à la mise en pratique de leur système d'éducation et de leur mode d'enseignement. Une cour d'école anglaise ne doit être exposée au nord ou à l'ouest, mais doit être orientée au sud ou à l'est [...]. ${ }^{56}$

No es esta la única fuente de la que es deudor -«en algunos datos»Repullés, quien en algunos de sus párrafos parece haber tomado directamente textos de los arquitectos franceses Lequeux, sobre escuelas primarias, y Desiré Laverdant, sobre guarderías, ${ }^{57}$ publicados todos ellos en la Revue Générale de L'architecture. De nuevo y a modo de ejemplo, se comparan ahora textos de Repullés y Lequeux glosando la escuela pública:

Porque, en efecto, las escuelas públicas son, en unión de los cursos populares y gratuitos, entre los que comprendemos las explicaciones religiosas, los únicos lugares donde el hombre llega a conocer la divina esencia de su alma; y son también, después del templo y la casa paterna, el local más digno de respeto, donde el niño aprende a desarrollar su inteligencia y comprende todo lo que puede conseguir con el trabajo y la instrucción.= Deber es, pues, y muy sagrado para los encargados del gobierno de los pueblos, extender cuanto les sea dable la instrucción, como cimiento

\footnotetext{
55 Repullés, Disposición, Construcción y Mueblaje, 11.

56 Narjoux, Les Écoles Publiques en France et en Angleterre, 82-3.

${ }^{57}$ Desiré Laverdant, "Architecture communale. Crèches», Revue Générale de l'Architecture et des travaux publics (1851): 161-9.
} 
del buen progreso, de la verdadera civilización. Que siendo la ignorancia lepra del entendimiento y conduciéndole a un embrutecimiento vergonzoso, a cualquier precio ha de procurarse que desaparezca. Elévese algo el nivel inferior de los conocimientos humanos para acercarle más al superior; que a menores distancias, más fácilmente se entenderán los hombres. ${ }^{58}$

Les écoles primaires communales sont, avec les cours publics et gratuit des villes, les seuls lieux où l'instruction soit donné aux pauvres; les écoles primaires sont, après l'église, où l'homme apprend à connaître la divine essence de son âme, et, je dois dire, après le toit paternel, malgré de tristes exceptions, le lieu le plus respectable où l'enfant apprend a développer son intelligence; [...] Le devoir du gouvernement, celui de l'autorité, est de reprendre cette instruction primaire sur tous les membres de la grande famille française, de les forcer même à recevoir cette instruction, comme dans certains temps on forçait à recevoir les secours de l'art pour les maladies du corps. L'ignorance absolue n'est-elle pas une lèpre de l'intelligence? Ne conduit-elle pas à un abrutissement honteux pour l'humanité? Il faut donc à tout prix que cette lèpre disparaisse; il faut élever le niveau inférieur des connaissances humaines en France; cela le rapprochera du niveau supérieur, et la distance étant mois grande, les hommes seront plus près de s'entendre. ${ }^{59}$

Entre las escuelas extranjeras que podrían adoptarse como modelos a imitar en España destaca Repullés las francesas, y propone seis ejemplos concretos: "los grupos escolares de las calles Alesia, Barbanegra [sic], Curial y Laugier (París); la escuela de Batignolles-Monceaux (Sena); la rural de Sully, la Tour [sic]». ${ }^{60}$ Es interesante constatar que, de las seis, cinco aparecen citadas consecutivamente en el libro de Narjoux sobre Francia e Inglaterra -los grupos escolares de París y la escuela rural de Sully-la-Tour ${ }^{61}$-; mientras que la de Batignolles-Monceaux

\footnotetext{
${ }_{58}$ Repullés, Disposición, Construcción y Mueblaje, 2.

${ }^{59}$ Lequeux, «Édifices pour l’Instruction Publique. Écoles Primaires», 259.

${ }^{60}$ Repullés, Disposición, Construcción y Mueblaje, 82.

${ }^{61}$ Narjoux, Les Écoles Publiques en France et en Angleterre, 179, 182, 184, 187 y 191.
} 
procede de uno de los artículos de Lequeux que Repullés utilizó en la confección de su libro. ${ }^{62}$ En lo referente a las escuelas inglesas, se limita el autor español a traducir lo que dice Narjoux de ellas y a reproducir los mismos modelos: las escuelas londinenses de West Ferry Road-ejemplo del sistema inglés de enseñanza-, de Johnson Street -ejemplo del sistema prusiano- y la de Wornington Road. ${ }^{63}$

\section{UNA ESCUELA MODELO PARA MADRID ${ }^{64}$}

En octubre de 1869, año pródigo en este tipo de certámenes, el Ayuntamiento de Madrid convocó un concurso de proyectos para construir una Escuela Modelo en el solar del antiguo Convento de las Maravillas. Pero lo hizo con un plazo muy exiguo, por lo que muy pocos fueron los arquitectos presentados. Los proyectos premiados fueron, en primer lugar el de Emilio Rodríguez Ayuso, a quien correspondió el encargo facultativo, y en segundo el de Enrique Repullés y Vargas, distinguido con un accésit honorífico. ${ }^{65}$ El edificio, concluido en 1885 tras muchas vicisitudes en su construcción, fue en su día el centro de enseñanza más moderno del país, dotado con material pedagógico de vanguardia adquirido en Suiza y Bélgica.

El Ayuntamiento de Madrid había establecido con anterioridad al concurso unas instrucciones para la redacción de los proyectos en las que se detallaban de forma exhaustiva las características y programa que el edificio había de cumplir. ${ }^{66}$ Según lo dispuesto en ellas, la escuela debía destinarse a la instrucción primaria y contar con cuatro clases: una para párvulos, otra para niñas y dos para niños, estas últimas contiguas y con posibilidad de unirse. Cada una de las clases debía ser capaz

\footnotetext{
${ }^{62}$ Lequeux, «Édifices pour l’Instruction Publique. Écoles Primaires Communales», 18-28.

${ }^{63}$ Repullés, Disposición, Construcción y Mueblaje, 82-3 y Narjoux, Les Écoles Publiques en France et en Angleterre, 231-8.

${ }^{64}$ Véanse: Repullés, Disposición, Construcción y Mueblaje, 76-78, Burgos, La arquitectura del aula, 19-22 y Rodríguez, Arquitectura escolar, 160-5.

${ }_{65}$ De nuevo encontramos a Rodríguez Ayuso y Repullés participando en un concurso de proyectos, aunque ahora por separado. Verdaderamente, fue un año prolífico para ambos este de 1869, aunque Repullés habrá de esperar hasta 1902 para poder ver en pie un edificio escolar proyectado por él, las escuelas Alfonso XII de Madrid [Pozo, Urbanismo y educación, 134-5] y [Rodríguez, Arquitectura escolar, 198-204].

${ }^{66}$ Repullés, Disposición, Construcción y Mueblaje, 98-100.
} 
para setenta u ochenta alumnos. Los accesos debían ser independientes para cada sexo, pudiendo servir el de niñas para los párvulos.

Partiendo de estos condicionantes, los dos arquitectos llegaron a esquemas en planta bastante similares: en ambos casos se trata de edificios compactos con patio interior, ajustados a las alineaciones que marcan la calle Daoiz y Velarde y la plaza del Dos de Mayo. Los dos proyectos, sin embargo, adolecen del defecto ya comentado antes en relación con la escuela de Washington: la simetría llevada al extremo conduce a asignar orientaciones diferentes para las clases.

Tras un primer análisis comparativo de las dos soluciones, se aprecia que Repullés quiso cumplir más rigurosamente que Rodríguez Ayuso las imposiciones de las bases, y esto en detrimento de una mayor claridad y limpieza de su propuesta y a costa de una mayor ocupación del solar. El proyecto ganador (figura 12), en cambio, responde a un esquema más claro, organizado en torno a un eje de simetría paralelo a la calle Daoiz y Velarde y compuesto de tres bandas: las laterales con clases y despachos, y la central organizando las circulaciones en torno al patio.

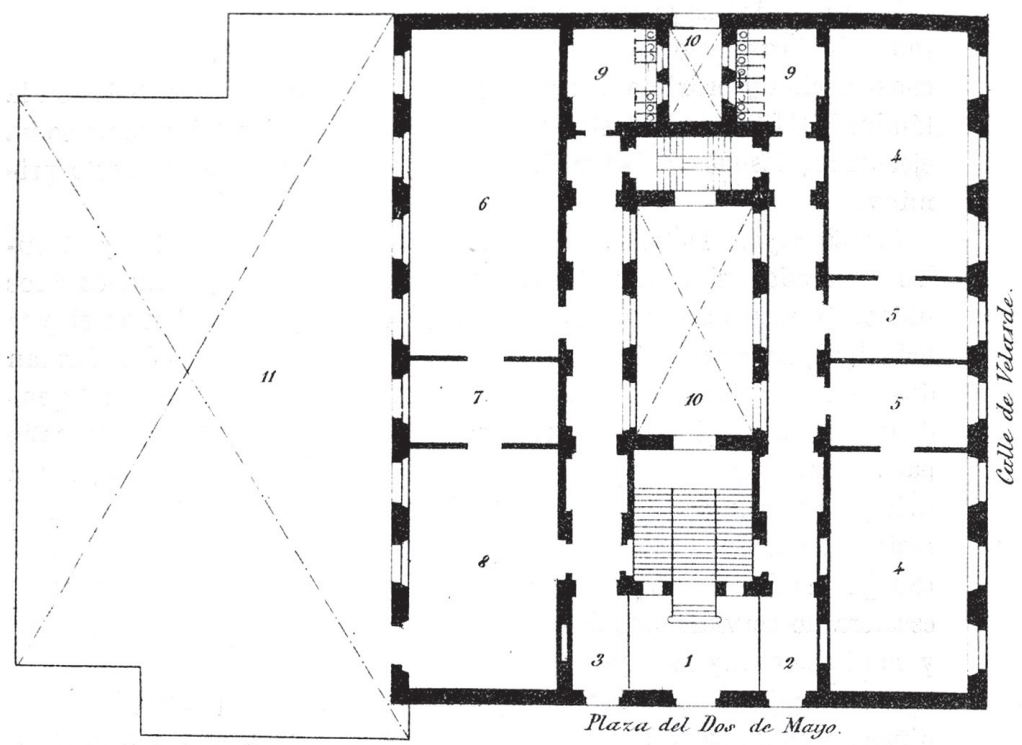

Figura 12. Proyecto para la Escuela Modelo de Madrid. Planta baja. Arq.: Rodríguez Ayuso [Repullés, Disposición, Construcción y Mueblaje, Lámina VIII]. 


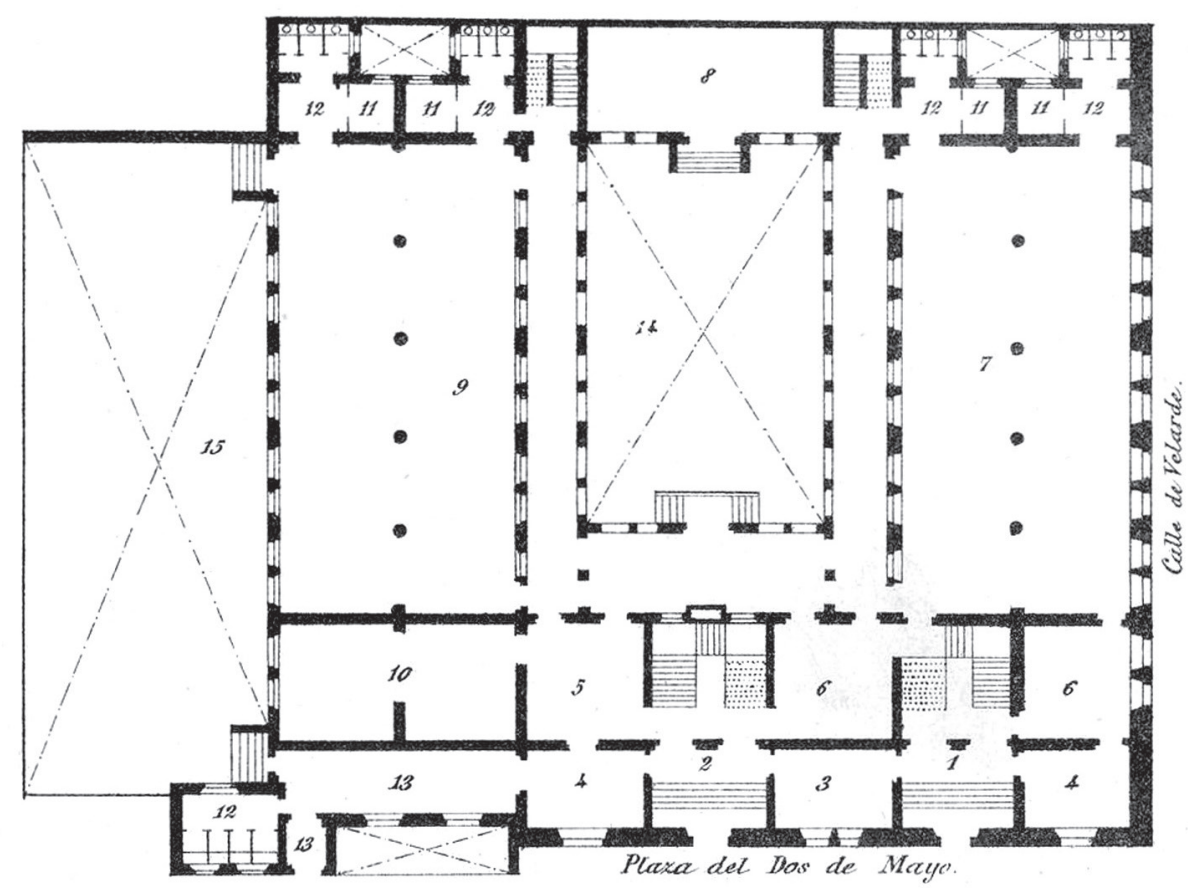

Figura 13. Proyecto para la Escuela Modelo de Madrid. Planta baja. Arq.: E.M. Repullés [Repullés, Disposición, Construcción y Mueblaje, Lámina IX].

Pero, por encima de todo lo dicho, la diferencia más notable entre las dos propuestas estriba en la concepción de la clase. En el proyecto de Repullés (figura 13) la clase -un espacio de 9 × 20 metros que, debido a la excesiva anchura, está dividido en dos por una hilera de columnas de fundición- sigue anclada en el modelo de clase masiva fundamentada en el sistema mutuo de enseñanza. En cambio, su amigo y compañero Rodríguez Ayuso opta por una clase de dimensiones más reducidas e iluminación unilateral, más acorde con el nuevo rumbo de la pedagogía.

El actual CEIP Pi i Margall es el resultado de la profunda reforma que en 1933 Bernardo Giner de los Ríos llevó a cabo en la Escuela Modelo. La reforma consistió, en primer lugar, en convertir la tercera planta -inicialmente destinada a viviendas- en una planta más al servicio del grupo escolar, y, en segundo, en dotarlo de una imagen más acorde con los tiempos: 
Aparte de todas las demoliciones [...], diremos aquí que también será rasada la cantería que forma los abultados decorativos de las fachadas, como son las jambas de los huecos, crestería de coronación de la casa, escudos e impostas, con objeto de obtener las fachadas desprovistas de ornamentación, [...], para lo cual además se hará un picado de todos ellos para poder ser después enfoscados y revocados a la tirolesa. ${ }^{67}$

La cubierta primitiva fue sustituida por una terraza plana con objeto de ampliar la superficie destinada a juego de los niños, decisión que, probablemente, llevó a Giner a actuar drásticamente sobre la imagen del edificio. Actualmente solo es posible encontrar la huella de Rodríguez Ayuso en la escalera principal. A juicio de Pedro Navascués, «su estilo no tenía nada de neomudéjar, acercándose más bien a un neogriego típico, con una forma muy característica de rematar los huecos con dinteles en piedra que acusan lo que podríamos llamar antefijas, dos en los extremos vistas de perfil y una central de frente».68

\section{LAS ESCUELAS DE DON LUCAS AGUIRRE EN CUENCA Y MADRID ${ }^{69}$}

Lucas Aguirre y Juárez, hombre de talante liberal y progresista, había nacido en Cuenca en 1800 en el seno de una familia dedicada a los negocios y perteneciente a la alta burguesía local. En 1860 se trasladó a Madrid, donde pasó sus últimos años comprometido con la educación de los sectores más desfavorecidos. El filántropo Aguirre dispuso que a su muerte fueran liquidadas todas sus propiedades $\mathrm{y}$, con el producto de las mismas, se fundaran escuelas en tres enclaves concretos relacionados con su historia personal. La primera de ellas, de 1868 y única establecida en vida de Aguirre, fue la escuela de Siones de Mena, pequeña localidad burgalesa donde había nacido su padre. Tras su fallecimiento en 1873, vinieron las de Cuenca, donde él mismo había nacido, y Madrid, que tan

\footnotetext{
${ }^{67}$ Bernardo Giner de los Ríos, Proyecto de reforma y ampliación del Grupo Escolar Pi y Margall (Madrid), julio de 1933, Archivo General de la Administración, Educación, caja 32/552. Tomado de: Rodríguez, Arquitectura escolar, 162.

${ }_{68}$ Pedro Navascués Palacio, Arquitectura y arquitectos madrileños del siglo XIX (Madrid: Instituto de Estudios Madrileños, 1973), 228. Tomado de: Rodríguez, Arquitectura escolar, 163.

${ }^{69}$ Véanse: Repullés, Disposición, Construcción y Mueblaje, 78-9; Burgos, La arquitectura del aula, 30-2 y Rodríguez, Arquitectura escolar, 165-72.
} 
bien le acogió en sus últimos años. Con el capital sobrante se crearía un legado cuya renta había de destinarse al sostenimiento de las escuelas.

Trece años transcurrieron desde la muerte de Don Lucas hasta la materialización de las escuelas. La primera en ser inaugurada fue la de Madrid, el 18 de octubre de 1886. Su emplazamiento en la calle de Alcalá, junto al parque del Retiro, no era caprichoso: se había escogido deliberadamente para que -al decir de Rodolfo Llopis-cuantos fueran a los toros, tanto al ir como al volver, tuvieran que toparse forzosamente «con un soberbio edificio que les hable de cultura y les reproche sus bárbaras aficiones...». ${ }^{70} \mathrm{La}$ nueva plaza de toros de Madrid, edificio que se tiene como iniciador de la corriente arquitectónica neomudéjar (la misma de las Escuelas Aguirre madrileñas), había sido inaugurada en 1874 según proyecto de Rodríguez Ayuso y Álvarez Capra. Quizás ello contribuyó a la designación del primero de los arquitectos citados, quien se hallaba inmerso en ese momento en la construcción de la Escuela Modelo, para proyectar las Escuelas Aguirre.

\section{Las Escuelas Aguirre de Cuenca}

Las escuelas de Cuenca fueron inauguradas igualmente en 1886, sin embargo habían sido proyectadas con anterioridad a las de Madrid, como prueba su inclusión en el libro de Repullés. Aunque habitualmente se las denomine en plural, se trata de un único edificio con dos clases, una para cada sexo, totalmente independientes (figura 14). Tal como fue proyectado, ${ }^{71}$ el edificio consta de un cuerpo central de dos pisos y dos laterales de uno solo con las clases; el cuerpo central se interna en el solar bastante más que los laterales, dedicándose en planta baja a galerías y en la principal a viviendas de los maestros.

Las dos escuelas son completamente simétricas y constan de un vestíbulo al que se une una pequeña sala de espera. Una puerta comunica el vestíbulo con la clase y otra con la galería cubierta -de $24 \mathrm{~m}$ de longitud

\footnotetext{
${ }^{70}$ Rodolfo Llopis Ferrándiz, Las ideas de Don Lucas Aguirre (Cuenca: Ruiz de Lara, 1924), 25. La plaza de Toros proyectada por Rodríguez Ayuso y Álvarez Capra fue sustituida en 1934 por la actual de Las Ventas. En el solar que ocupaba la primera se alza hoy el Palacio de los Deportes de la Comunidad de Madrid, distante apenas un kilómetro de las Escuelas Aguirre.

${ }^{71}$ El edificio construido, actualmente Centro Cultural Aguirre, no se ajusta exactamente al proyecto de Rodríguez Ayuso. La longitud de la clase izquierda se redujo considerablemente, y no existen las galerías cubiertas, que, si se construyeron, han sido demolidas.
} 
por 5,50 de anchura (figura 14, $\mathrm{n}^{\circ} 8$ y $8^{\prime}$ )-, cuyos primeros cinco metros penetran en el pabellón central. Este primer tramo de galería está en comunicación directa con lavabo y guardarropa, y también con la clase. Los retretes se disponen en la forma clásica, es decir, como pequeños apéndices junto a la mesa del profesor para su mejor control por este.

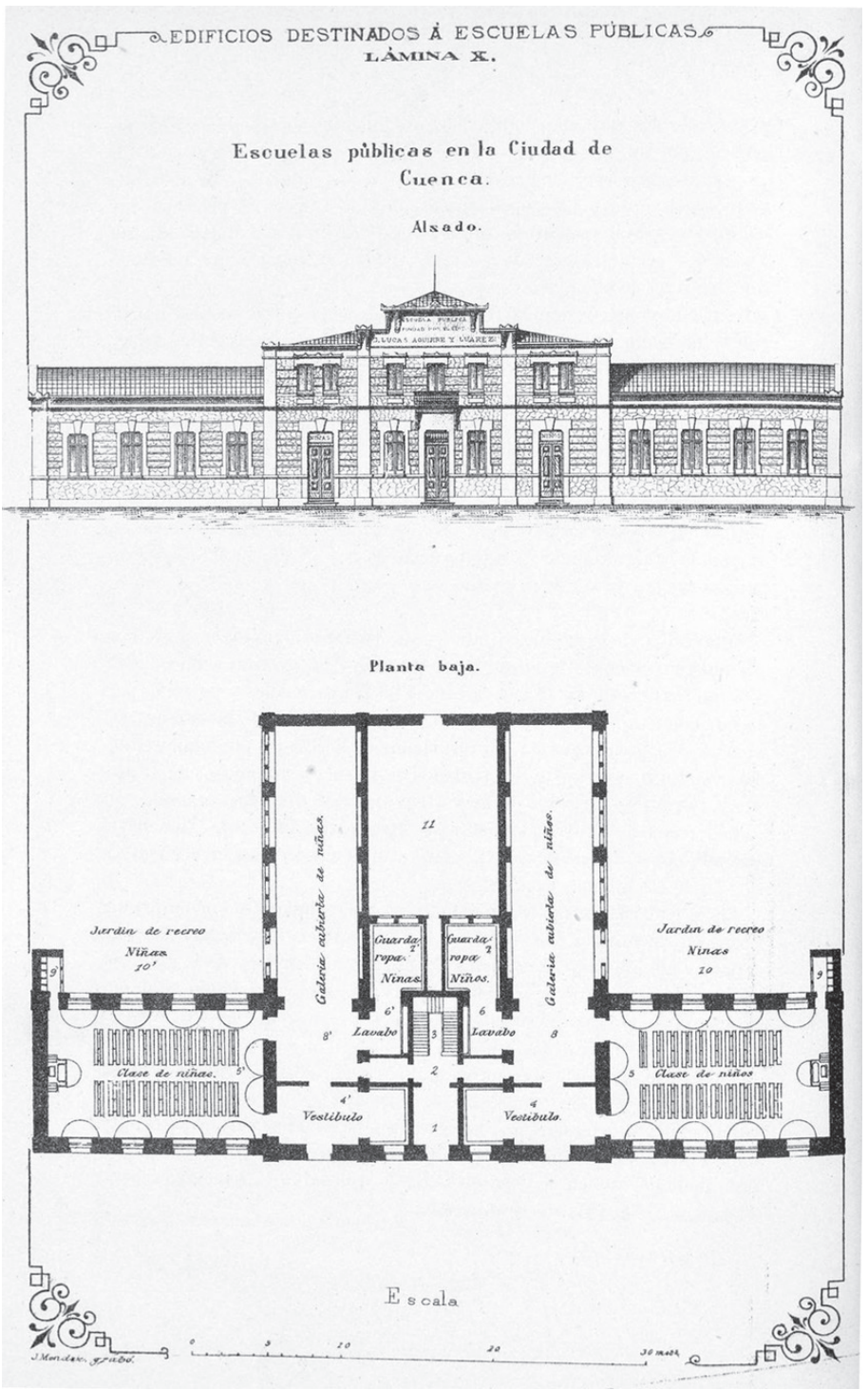

Figura 14. Escuelas Aguirre de Cuenca. Planta baja. Arq.: Rodríguez Ayuso [Repullés, Disposición, Construcción y Mueblaje, Lámina X]. 
Entre las galerías cubiertas se inscribe un espacio rectangular (figura 14, $\left.n^{\circ} 11\right)$ que en proyecto carece de cubierta pero que, con el tiempo, podría llegar a cubrirse para alojar un gimnasio, en cuyo caso recibiría luz, bien cenitalmente, bien por el muro testero. ${ }^{72}$ Es este un ámbito muy interesante que anticipa la solución más compleja empleada en las Escuelas Aguirre de Madrid.

Cada una de las clases, de 9 x 15 m, es capaz para 100 alumnos y recibe luz bilateral, no por los testeros, como ocurría en el tipo adicional. La disposición del mobiliario da a entender que el sistema de enseñanza para el que está diseñada la clase sigue siendo el de las secciones reunidas en torno a semicírculos adosados a las paredes, sistema que obliga a elevar la altura del antepecho de los huecos a dos metros sobre el piso de la clase.

Según Repullés, el proyecto de Rodríguez Ayuso para Cuenca se basaba en el «tipo adicional» de los proyectados por la Escuela de Arquitectura (figura 6)..$^{73}$ Cuando más arriba nos referíamos a esta misma afirmación, expresamos nuestro parecer de que más bien ambos esquemas procedían de uno importado de Francia: la mairie-école, y, entre los posibles modelos en que el tipo adicional pudo basarse, proponíamos la escuela del barrio de Petit-Monrouge (París) como más probable. Si se comparan las plantas de las escuelas conquense y parisina (figuras 8 y 14), se llega a la conclusión de que el parecido entre ambas es en este caso mayor: la escuela de Cuenca podría considerarse como una evolución de la de Petit-Monrouge en la que el jardín delantero ha sido ocupado con los vestíbulos y la prolongación de los préaux couverts (en Cuenca, galerías cubiertas), tal como Vacquer recomendaba respecto a la de París. ${ }^{74}$

Es posible encontrar reminiscencias de las Escuelas Aguirre de Cuenca, tan difundidas gracias al libro de Repullés, en otras escuelas posteriores. Este es el caso de las escuelas de San Miguel en Palencia, actual CEIP Jorge Manrique, proyectadas en 1886 por el arquitecto municipal Cándido Germán. Si se prescinde de las clases de párvulos añadidas y de la adaptación de las restantes a la enseñanza simultánea, el parecido entre ambas es notable. ${ }^{75}$

\footnotetext{
72 Repullés, Disposición, Construcción y Mueblaje, 79.

${ }^{73}$ Repullés, Disposición, Construcción y Mueblaje, 78-9.

${ }^{74}$ Vacquer, Bâtiments scolaires récemment construits, 11.

75 Véase en: Lourdes Espinilla y José Luis González, «Génesis de la primera "Escuela de Párvulos” en Palencia capital (1857-1910). La Insigne figura de D. Vicente Inclán», Tabanque 20 (2006-2007): 137-66, 142.
} 


\section{Las Escuelas Aguirre de Madrid}

La planta del edificio se compone de tres pabellones en U que delimitan un espacio rectangular, a su vez dividido en dos por una cuarta crujía situada sobre el eje de simetría del conjunto (figura 15). De las tres crujías exteriores, las dos laterales se destinan a albergar las aulas en planta baja y las viviendas en la superior. La central alberga los accesos y despachos en la baja y el salón de juntas y la biblioteca en la primera. La cuarta crujía, la central, se manifiesta en fachada por una alta torre -verdadero hito urbano- y reúne la escalera, un patio de luces y los servicios higiénicos. El resto de la planta baja se ocupa con dos espacios cubiertos a tres aguas que dan acceso a las clases y que, por su gran dimensión, podrían servir como gimnasios. De nuevo se perciben aquí las señas distintivas de Rodríguez Ayuso, que lo distinguían claramente de Repullés en la Escuela Modelo: el orden inmaculado de la planta y la coherencia entre interior y exterior.

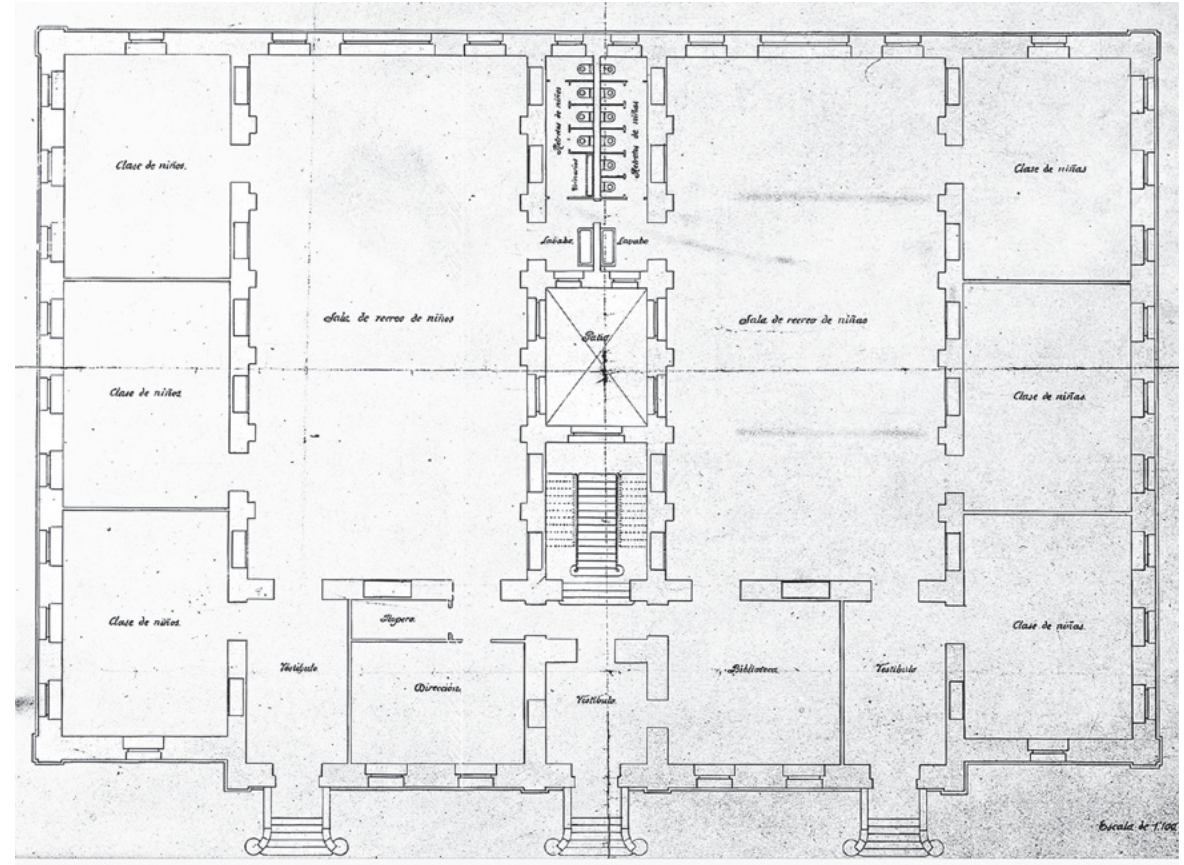

Figura 15. Escuelas Aguirre de Madrid. Planta baja. Arq.: Rodríguez Ayuso [Archivo de Villa de Madrid: 16-281-21]. 
Las Escuelas Aguirre de Cuenca y de Madrid fueron proyectadas por Rodríguez Ayuso más o menos simultáneamente y responden a unos criterios muy similares. De la comparación de sus plantas se concluye que las de Madrid parecen ser el resultado de replegar sobre el cuerpo central, a causa de la estrechez del solar, las alas que en Cuenca estaban extendidas. Lo que en Cuenca era galería cubierta y abierta al patio, pasa a ser en Madrid un espacio cerrado e iluminado cenitalmente y por uno de sus testeros. Dicho de otro modo, Ayuso quiso poner en práctica en Madrid esa dependencia que en Cuenca quedó en simple ensayo y que era el espacio comprendido entre las dos galerías, del que Repullés decía que podía cubrirse en un futuro y utilizarse como gimnasio (figura 14, $\mathrm{n}^{\circ} 11$ ).

Ahora bien, ¿por qué las clases son diferentes en uno y otro caso? En Cuenca, la clase tiene un ancho de nueve metros, mientras que aquí -al igual que en la Escuela Modelo- la anchura no llega a siete metros. Lo que tienen de común estos dos últimos casos es que el número de plantas superior a uno. En Cuenca el ancho de nueve metros se cubre mediante cerchas y sin necesidad de columnas intermedias. Al no tener esa posibilidad en las plantas bajas de los otros dos casos madrileños, es necesario reducir la anchura si se quiere prescindir de las columnas intermedias. Rodríguez Ayuso se encontró en una tesitura similar a la de los arquitectos franceses de aquel tiempo, que para eliminar las columnas en las clases tuvieron que reducir las luces a cubrir. Tal como señala Châtelet, la solución de un problema estructural obligó a modificar la capacidad del aula y, como consecuencia de ello, su concepto. ${ }^{76}$

La procedencia del patio cubierto empleado por Rodríguez Ayuso en Madrid, espacio bastante atípico en la arquitectura escolar española, es explicable como influjo de La Escuela Modelo de Bruselas, muy conocida en toda Europa desde su exhibición en la Exposición Universal de $1878 .{ }^{77} \mathrm{La}$ escuela parisina de la calle Keller, proyectada por Durand-Billion en 1844 y considerada un precedente de la Escuela

\footnotetext{
76 Anne-Marie Châtelet, «L'école prend forme», en Paris à l'école, qui a eu cette idée folle..., ed. A. M. Châtelet (París: éditions du Pavillon de l’Arsenal, 1993), 78-89, 85.

77 Francisco Javier Rodríguez Méndez, «Ecos en España de la Escuela Modelo de Bruselas», en Influencias belgas en la educación española e iberoamericana, ed. José M ${ }^{\mathrm{a}}$ Hernández (Salamanca: Ediciones Universidad de Salamanca, 2019), 291-302.
} 
Modelo de Bruselas, ${ }^{78}$ pudo también haber influido en Rodríguez Ayuso, bien a través de la Revue Générale de l'Architecture, ${ }^{79}$ o del libro de Vacquer que hemos citado anteriormente como posible fuente de Rodríguez Ayuso y Repullés. ${ }^{80}$

\section{LOS JARDINES DE LA INFANCIA DE MADRID ${ }^{81}$}

Las primeras noticias sobre los jardines de infancia se difundieron en España a partir de la mitad del siglo XIX. Aunque las primeras experiencias prácticas del método Froebel, tanto en Madrid como en Barcelona, datan de esta fecha, los jardines de infancia -o Kindergarten- propiamente dichos no se introdujeron verdaderamente hasta la creación en Madrid, por el Ministerio de Fomento, del primer jardín de infancia español basado en el sistema Froebel, a construir en un solar situado en la calle Daoiz y Velarde, entre la Escuela Normal Central de Maestros y la Escuela Modelo. ${ }^{82}$

El arquitecto autor del proyecto y director de las obras fue Francisco Jareño, de quien ya se ha hablado con motivo de su concurrencia al concurso de modelos de escuelas públicas de 1869. El proyecto de Jareño se ajustaba notablemente al modelo de jardín de infancia propuesto por Fiedrich Froebel, que, en resumen y de acuerdo con las descripciones que de él se han divulgado, debía estar fuertemente conectado con el entorno natural y contar con una gradación de espacios: «cerrados, abiertos y de transición». ${ }^{83}$ Repullés y Vargas también prestó atención a este tipo de establecimiento escolar, al que dedicó

\footnotetext{
${ }^{78}$ Françoise Jurion-de Waha, «L'école en beauté, un exemple d'architecture pour l'enfant», Cahiers Bruxellois 1, XLVII (2015): 194-243, 206 y 218. La autora sitúa a la escuela de la calle Keller en la calle Charonne, pero se está refiriendo a la misma escuela proyectada por DurandBillion.

79 Joseph Uchard, «Écoles communales de la ville de Paris», Revue Générale de l'Architecture et des travaux publics (1862): 9-14.

80 Vacquer, Bâtiments scolaires récemment construits, 13-14 y láminas 11-15. Véanse las notas 22, 33 y 74 .

81 Véanse: Purificación Lahoz, «El modelo Fröebeliano de espacio-escuela. Su introducción en España», Historia de la educación 10 (1991): 107-133., Burgos, La arquitectura del aula, 22-24 y Rodríguez, Arquitectura escolar, 173-78.

${ }^{82}$ Lahoz, «El modelo Fröebeliano de espacio-escuela», 125.

${ }^{83}$ Lahoz, «El modelo Fröebeliano de espacio-escuela», 110.
} 
todo un epígrafe de su libro. ${ }^{84}$ De acuerdo con su descripción, la escuela froebeliana debía constar de cuatro clases donde agrupar a los niños según su grado de instrucción, clases que debían estar precedidas de un vestíbulo con guardarropa, despacho, locutorio y pequeña cocina-comedor. Junto con las dependencias básicas, Repullés menciona «un gran salón» -el gimnasio intelectual- que habría de servir para recreo y juegos en los días de mal tiempo. En la planta alta debían disponerse las viviendas para el conserje y el maestro. Por último, complemento indispensable del jardín de infancia, debían ser el «patio cerrado y espacioso» -dotado de abundante arbolado y casetas para los aseos y para guardar útiles y animales- y el jardín, dividido en las pequeñas parcelas para trabajo individual y las más grandes para trabajo común.

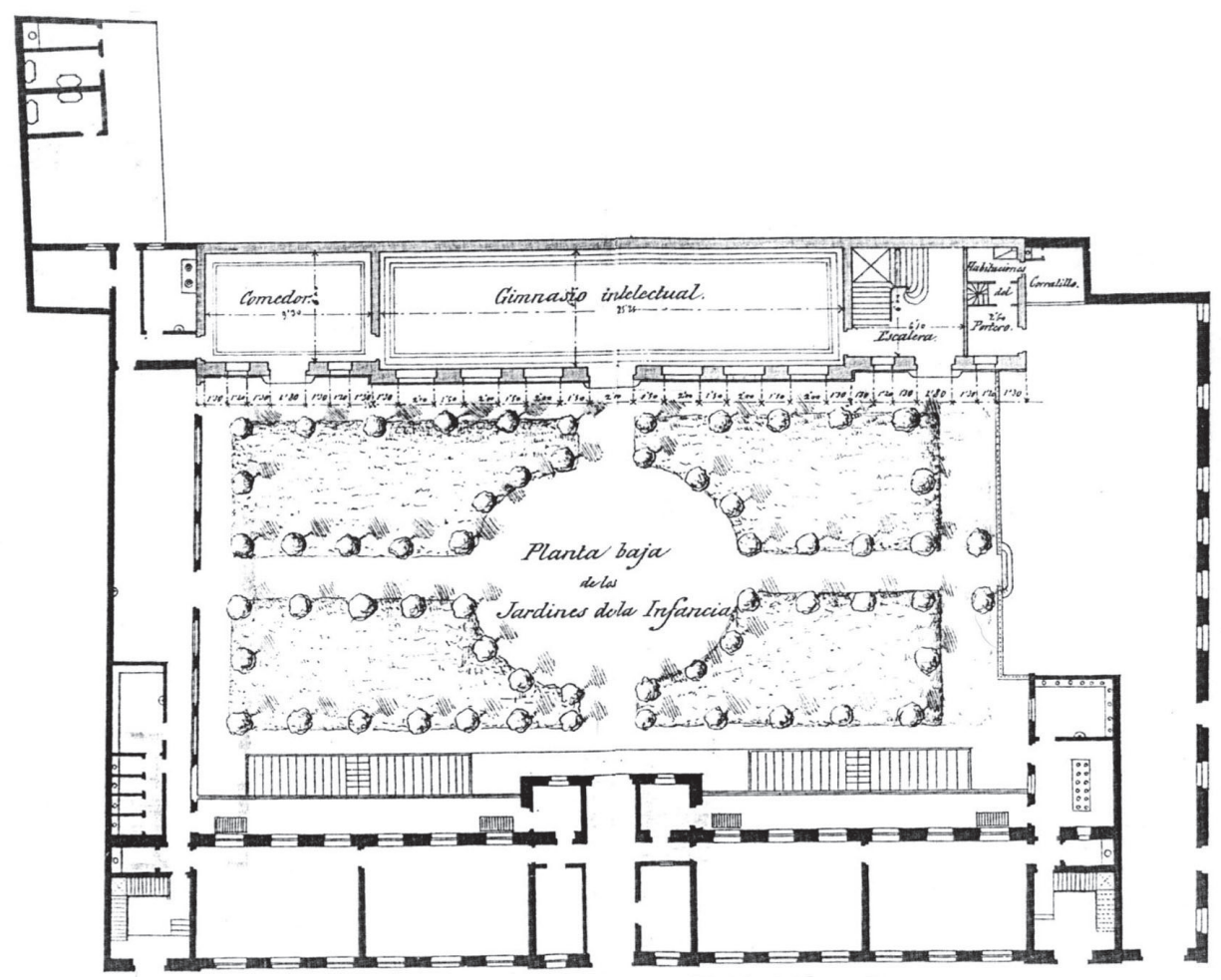

Figura 16. Planta baja de la escuela Jardines de la Infancia de Madrid. Arq.: Francisco Jareño [Archivo General de la Administración, Educación, Caja 32/8101].

${ }^{84}$ Repullés, Disposición, Construcción y Mueblaje, 32-5. 
El jardín de infancia madrileño fue comenzado en 1877 y se componía de varios pabellones adosados a los lados de la parcela rectangular que encerraban en su interior un extenso jardín (figura 16). La entrada se producía por la calle Daoíz y Velarde atravesando el pabellón principal, de dos plantas y una sola crujía, alineado a esta calle. Enfrente se situaba otro pabellón de una sola planta conteniendo el gimnasio y el comedor. Los dos pabellones estaban comunicados por una galería cubierta adosada al lindero oriental. ${ }^{85}$

El pabellón principal tenía una composición absolutamente simétrica. La entrada a la escuela se producía por el eje a través de un vestíbulo. En torno a él, y separadas entre sí por los pasos a las clases, se disponían cuatro dependencias destinadas a despachos y guardarropas. El cuerpo central así constituido se manifestaba en fachada por un pequeño saliente y estaba rematado superiormente por un frontón de estilo neogriego. Las clases se situaban, agrupadas de dos en dos, a ambos lados del cuerpo central; a falta de una segunda crujía, para llegar desde el vestíbulo a la más alejada era necesario atravesar la primera. Completaban la planta baja de este pabellón principal las entradas a las viviendas de la planta superior, con sus correspondientes escaleras. Los aseos, sobresalientes a ambos lados y en prolongación de los portales de las viviendas, tenían su acceso únicamente desde del patio.

El pabellón situado al otro lado del jardín se adosaba al lado meridional de la parcela y consistía en una sencilla construcción de planta baja y una sola crujía con cubierta a un agua. Albergaba la cantina escolar -comedor y cocina-, el "gimnasio intelectual» y la vivienda del jardinero. El gimnasio ocupaba la posición central y su entrada estaba situada sobre el eje de simetría. El trazado del jardín, consistente en cuatro parterres separados de los pabellones perimetrales y entre sí por dos caminos perpendiculares y un óvalo central, reforzaba la axialidad de la planta. Las restantes construcciones se reducían a la galería oriental de comunicación entre los dos pabellones y unos pequeños cobertizos para gallinero y baños al otro lado.

\footnotetext{
${ }^{85}$ De los espacios integrantes de un jardín de infancia enumerados por Repullés [Disposición, Construcción y Mueblaje, 34-5], el único que se echa en falta aquí es el destinado a huertos para trabajo individual y comunitario, del que Jareño hubo de prescindir a causa de la insuficiente extensión del solar.
} 
Las clases eran muy parecidas a las que el arquitecto propuso como idóneas en el concurso de 1869 y cuyas características aparecen reflejadas en la figura 10. Las dimensiones son las mismas en los dos casos: 20 por 30 pies ( 6 por 9 metros). La modulación de las ventanas es también la misma (tres por clase), pero en la escuela que nos ocupa Jareño optó por abrir huecos a calle y patio, contraviniendo lo dicho en su memoria respecto a la conveniencia de la iluminación unilateral. Para evitar distracciones de los niños, elevó los vierteaguas a dos metros del suelo, incumpliendo con ello otro de sus planteamientos.

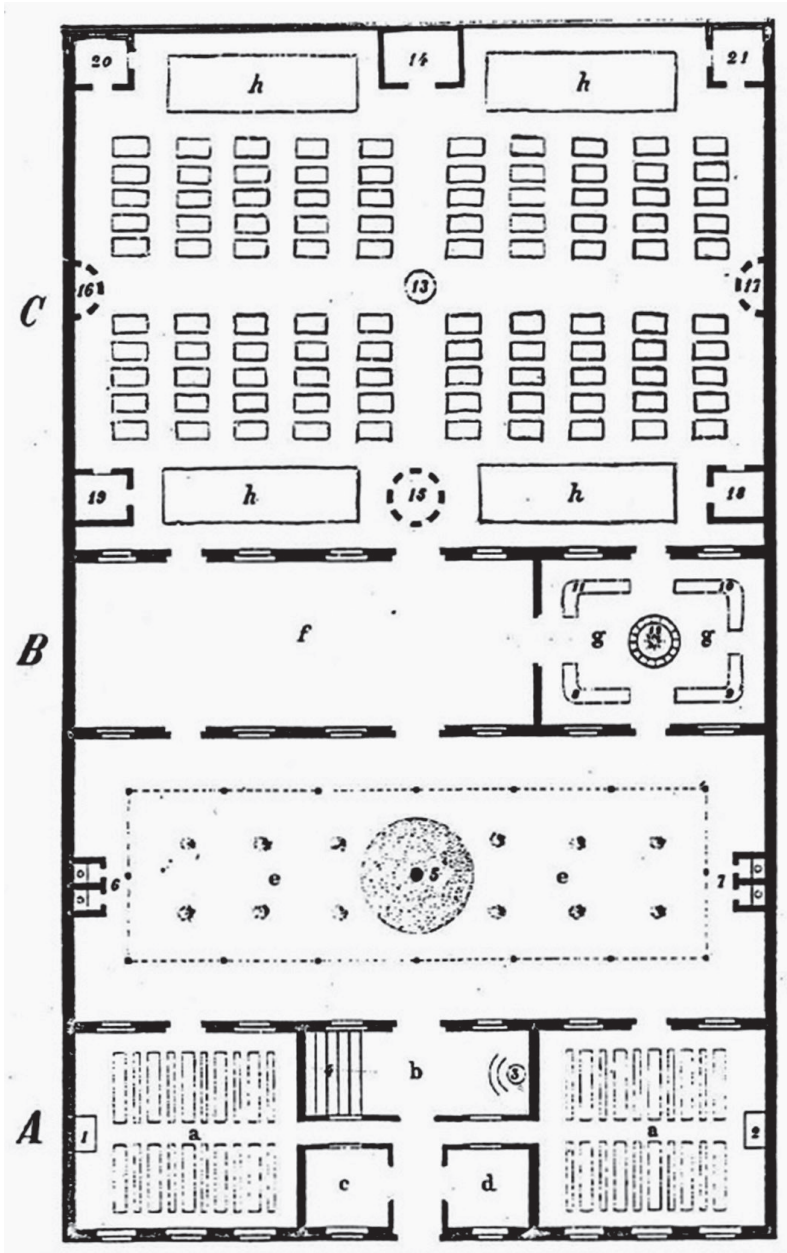

Figura 17. Jardín de infancia diseñado por Pedro de Alcántara García, según el modelo de Froebel [Lahoz, «El modelo Fröebeliano de espacio-escuela», 112]. 
Si se compara la planta de los Jardines de la Infancia madrileños con una escuela ideal organizada bajo los principios froebelianos, por ejemplo la diseñada por el pedagogo español Pedro de Alcántara García, ${ }^{86}$ la conclusión a que se llega es que el proyecto de Jareño se ajusta notablemente a ella (figura 17). Al igual que el modelo del pedagogo, la planta de Jareño se compone de un pabellón principal de una sola crujía, simétrico y con iluminación bilateral, con la entrada y el vestíbulo situados sobre el eje. En los dos casos el gimnasio, situado en el pabellón posterior, paralelo al principal, ocupa una superficie igual a la suma de la de las aulas. Tanto en uno como en otro caso, entre los dos pabellones se extiende el patio de juego con árboles y parterre circular central.

La importancia de este centro escolar como inspirador de la arquitectura escolar española deriva más bien de la pedagogía froebeliana que allí se llevó a cabo que de sus características espaciales. Es posible, no obstante, encontrar reminiscencias de ellas en las Escuelas Froebel de Pontevedra, proyectadas en 1912 por Antonio Flórez, que no podrían entenderse si no es desde la perspectiva del edificio concebido por Francisco Jareño cuarenta años antes. ${ }^{87}$

\section{CONCLUSIONES}

A pesar de haber sido distinguidos con el máximo galardón en el Concurso de modelos para escuelas públicas convocado en 1869, los proyectos de la Escuela de Arquitectura se basan en modelos difícilmente aplicables en nuestro país. El primer tipo responde a una tipología ensayada en Francia desde hacía tiempo, pero que en la fecha del concurso estaba prácticamente en desuso. El tercer tipo es sin duda el más deficiente a causa de la exagerada desproporción entre anchura y longitud del aula. El tipo adicional, pequeño grupo escolar con dos clases independientes y viviendas para los maestros, es el más aceptable de los cuatro propuestos por la Escuela de Arquitectura; y quizás por esa razón, se le ha venido atribuyendo el carácter de modelo en que se basan

\footnotetext{
${ }^{86}$ Lahoz, «El modelo Fröebeliano de espacio-escuela», 112.

87 Francisco Javier Rodríguez Méndez, «Influencias alemanas en la arquitectura escolar española», en La pedagogía alemana en España e Iberoamérica (1810-2010), ed. José $\mathrm{M}^{\mathrm{a}}$ Hernández (Valladolid: Castilla Ediciones, 2011), 194-224.
} 
las tan abundantes escuelas de cuerpo central de dos plantas y alas laterales destinadas a clases. Sin embargo, es necesario tener en cuenta una raíz común proveniente de Francia: la marie-école.

Los proyectos de Repullés y Rodríguez Ayuso tuvieron poca o nula aplicación práctica a causa, por un lado, del excesivo coste de dichos modelos y, por otro, de la penuria económica de los ayuntamientos, responsables de su construcción. Es indudable que el conocimiento y la experiencia de Francisco Jareño eran muy superiores a los reunidos por los ganadores del concurso, arquitectos recién titulados a la sazón. La adopción como preferentes de los proyectos de Jareño habría comportado unas consecuencias muy diferentes y un ahorro considerable en el plazo para comenzar a vislumbrar una solución al grave problema de la escolarización de la infancia.

El concurso de proyectos para Escuela Modelo de Madrid, también de 1869, reunió de nuevo a Repullés y Rodríguez Ayuso, pero esta vez como competidores. El ganador fue Rodríguez Ayuso, cuyo proyecto, aunque menos escrupuloso en el cumplimiento de las bases, respondía a un esquema más claro que el de Repullés. La concepción de la clase de este último sigue anclada en el modelo de clase masiva, en cambio, Rodríguez Ayuso opta por una clase de dimensiones más reducidas e iluminación unilateral.

El encargo de las Escuelas Aguirre de Cuenca y Madrid recayó en Rodríguez Ayuso en 1873 como consecuencia de sus éxitos anteriores. Ambas escuelas responden a unos criterios muy similares, con un diseño más compacto las de Madrid y englobando dos patios cubiertos, espacio importado y bastante atípico en las escuelas españolas. Las clases de Cuenca y Madrid difieren en su concepto: frente a las de Cuenca, de gran tamaño y adaptadas a la enseñanza mixta, las de Madrid son similares a las que empleó en la Escuela-modelo.

El primer jardín de infancia español fue comenzado en Madrid en 1877, según proyecto de Francisco Jareño, se componía de varios pabellones adosados a los lados de la parcela que encerraban en su interior un extenso jardín. El diseño de Jareño se ajustaba notablemente al modelo de jardín de infancia propuesto por Fiedrich Froebel, descrito en múltiples publicaciones. 
De los tres arquitectos protagonistas de este período fue Repullés el que menor provecho práctico obtuvo de su participación en el concurso de modelos de escuelas de 1869, pues, a pesar de la relevancia obtenida con la publicación de su libro, tuvo que esperar hasta 1902 para ver en pie una escuela erigida con proyecto suyo.

\section{Nota sobre el autor}

Francisco JaVIER Rodríguez Méndez (Salamanca, 1959) es arquitecto (1984) por la Escuela Técnica Superior de Arquitectura de Madrid (ETSAM). Doctor arquitecto (2004), por la misma Escuela, con la tesis «Arquitectura escolar en España 1857-1936. Madrid como paradigma», dirigida por Miguel Ángel Baldellou. Catedrático de Bachillerato (1984-1988 y 1993-1996). Arquitecto escolar de la provincia de Zamora (1988-1993). Profesor Titular de Escuela Universitaria en el Departamento de Construcción de la Universidad de Salamanca (1996-2009). Profesor Titular de Universidad en el Departamento de Construcción de la Universidad de Salamanca (2009-vigente). Autor de numerosas publicaciones en el campo de la arquitectura escolar. Libro: Aquellos colegios de ladrillo (2008). Artículos en: Historia y Memoria de la Educación (11, 2020), Artigrama (34, 2019), Historia de la Educación (38, 2019 y 25, 2007), Foro de Educación (12, 2014), P+C: proyecto y ciudad $(2,2011)$ y ARQSCOAL $(4,2006)$. Capítulos de libro en: Identidades y tránsitos artísticos en el exilio español de 1939 hacia Latinoamérica (2019), Ciencia e innovación en las aulas. Centenario del Instituto-Escuela (1918-1939) (2018), La arquitectura del Movimiento Moderno y la educación (2013), L'école de plein air. Une expérience pédagogique et architecturale dans l'Europe du XXe siècle (2003), Francia en la educación de la España contemporánea 1808-2008 (2011), La pedagogía alemana en España e Iberoamérica 1810-2010 (2011), Influencias belgas en la educación española e iberoamericana (2019), Influencias suizas en la educación española e iberoamericana (2016), Actas de las Jornadas Científicas de la Sociedad Española para el Estudio del Patrimonio Histórico Educativo (2012, 2014, 2016).

\section{REFERENCIAS}

Burgos Ruiz, Francisco. La arquitectura del aula. Nuevas escuelas madrileñas, 1868-1968. Madrid: Ayuntamiento de Madrid, 2007. 
Bouillon, Auguste. De la construction des maisons d'école primaire. París: Hachette, 1834.

Châtelet, Anne-Marie. "L'école prend forme». En Paris à l'école, qui a eu cette idée folle..., editado por A. M. Châtelet, 78-89. París: éditions du Pavillon de l'Arsenal, 1993.

Châtelet, Anne-Marie. La naissance de l'architecture scolaire. Les écoles élémentaires parisiennes de 1870 à 1914. París: Honoré Champion Editeur, 1999.

Châtelet, Anne-Marie. «Dialogue France-Allemagne sur l'architecture et la pédagogie». Proyecto Progreso Arquitectura 17 (2017): 16-27.

Espinilla Herrarte, María Lourdes y González Sánchez, José Luis. «Génesis de la primera "Escuela de Párvulos” en Palencia capital (1857-1910). La Insigne figura de D. Vicente Inclán». Tabanque 20 (2006-2007): 137-66.

Granier, Christine y Marquis, Jean-Claude. "Une enquête en cours: La maison d'école au XIXe siècle». Histoire de l'éducation 17 (1982): 31-46.

Hernández Díaz, José María. «Espacios escolares, contenidos, manuales y métodos de enseñanza». En Historia de la educación en la España contemporánea. Diez años de investigación, coordinado por Jean-Louis Guereña, Alejandro Tiana y Julio Ruiz, 191-213. Madrid: Ministerio de Educación Cultura y Deporte, C.I.D.E., 1994.

Jareño y Alarcón, Francisco. Memoria facultativa sobre los Proyectos de Escuelas de Instrucción Primaria... Madrid: Imprenta del Colegio Nacional de Sordo-mudos y Ciegos, 1871.

Jurion-de Waha, Françoise. «L'école en beauté, un exemple d'architecture pour l'enfant». Cahiers Bruxellois 1, XLVII (2015): 194-243.

Kluss, Adolf y Kammenhüber, J. W. «Schulgebäude zu Washington». Allgemeine Bauzeitung mit Abbildungen (1868-69): 34-35 y 186-8.

Lahoz Abad, Purificación. «El modelo Fröebeliano de espacio-escuela. Su introducción en España». Historia de la Educación 10 (1991): 107-33.

Laverdant, Desiré. "Architecture communale. Crèches». Revue Générale de l'Architecture et des travaux publics (1851): 161-9.

Lequeux, Paul-Eugène. «Édifices pour l'Instruction Publique. Écoles Primaires». Revue Générale de l'Architecture et des travaux publics (1849): 258-61, planchas XXVI- XXVII.

Lequeux, Paul-Eugène. «Édifices pour l'Instruction Publique. Écoles Primaires Communales». Revue Générale de l'Architecture et des travaux publics (1851): 18-28, planchas II-VII.

Llano Díaz, Ángel. «Notas sobre el espacio rural escolar en Cantabria (18501936)» [en línea]. Cabás: Revista del Centro de Recursos, Interpretación y Estudios en materia educativa (CRIEME) de la Consejería de Educación del Gobierno de Cantabria (España) [publicación seriada en línea] 1 (2009). 
http://revista.muesca.es/articulos/66-notas-sobre-el-espacio-rural-en-cantabria-1850-1936 (consultado el 26 de mayo de 2020).

Llopis Ferrándiz, Rodolfo. Las ideas de Don Lucas Aguirre. Cuenca: Ruiz de Lara editores, 1924.

Martí Alpera, Félix. Por las escuelas de Europa. Valencia: Imprenta Vives, 1904. Narjoux, Félix. Les Écoles Publiques en France et en Angleterre. Construction et installation. París: A. Morel et Cie., 1877.

Navascués Palacio, Pedro. Arquitectura y arquitectos madrileños del siglo XIX. Madrid: Instituto de Estudios Madrileños, 1973.

Ortueta Hilberath, Elena de. «Los modelos de escuelas destinados a los centros de educación primaria pública avalados por el Negociado de Arquitectura Escolar del Ministerio de Instrucción Pública y Bellas Artes». Norba: Revista de arte 17 (1997): 165-92.

Repullés y Vargas, Enrique María. «Nuevas escuelas de instrucción primaria en Cuenca». Anales de la construcción y de la industria II (1877): 88-90.

Repullés y Vargas, Enrique María. «Edificios destinados a escuelas públicas de instrucción primaria». Anales de la construcción y de la industria II (1877): 212-5, 234-6, 246-9, 290-5, 310-3, 321-5, 340-2 y 358-61.

Repullés y Vargas, Enrique María. «Edificios destinados a escuelas de instrucción primaria». Anales de la construcción y de la industria III (1878): 1-4, 21-6, 53-5, 86-9 y 145-7.

Repullés y Vargas, Enrique María. Disposición, Construcción y Mueblaje de las Escuelas Públicas de Instrucción Primaria. Madrid: Imprenta de Fortanet, 1878.

Repullés y Vargas, Enrique María. «Obras arquitectónicas de Rodríguez Ayuso». En Biografía y obras arquitectónicas de Emilio Rodríguez Ayuso, editado por Santiago Castellanos y Enrique M $^{\mathrm{a}}$ Repullés, 17-31. Madrid: Imprenta y litografía de los huérfanos, 1892.

Rodríguez Méndez, Francisco Javier. «Arquitectura escolar en España 18571936. Madrid como paradigma». Tesis doctoral, Universidad Politécnica de Madrid, 2004.

Rodríguez Méndez, Francisco Javier. «Influencia francesa en la arquitectura escolar española». En Francia en la educación de la España contemporánea (1808-2008), editado por José Ma Hernández, 185-218. Salamanca: Universidad de Salamanca, 2011.

Rodríguez Méndez, Francisco Javier. «Influencias alemanas en la arquitectura escolar española». En La pedagogía alemana en España e Iberoamérica (1810-2010), editado por José M ${ }^{\mathrm{a}}$ Hernández, 194-224. Valladolid: Castilla Ediciones, 2011.

Rodríguez Méndez, Francisco Javier. «La huella de Adolf Cluss en la escuela graduada de Cartagena». Foro de Educación 12 (2014): 69-89. 
Rodríguez Méndez, Francisco Javier. «Ecos en España de la Escuela Modelo de Bruselas». En Influencias belgas en la educación española e iberoamericana, editado por José Ma Hernández Díaz, 291-302. Salamanca: Ediciones Universidad de Salamanca, 2019.

Uchard, Joseph. "Écoles communales de la ville de Paris». Revue Générale de l'Architecture et des travaux publics (1862): 9-14.

Vacquer, Théodore. Bâtiments scolaires récemment construits en France et propres à servir de types pour les édifices de ce genre. París: Caudrilier, 1863.

Viñao Frago, Antonio. Innovación pedagógica y racionalidad científica. La escuela graduada pública en España (1898-1936). Madrid: Akal, 1990.

Viñao Frago, Antonio. «El espacio escolar. Introducción». Historia de la Educación 12-13 (1993-94): 11-6.

Viñao Frago, Antonio. "Construcciones y edificios escolares durante el sexenio democrático (1868-1874)». Historia de la Educación 12-13 (1993-94): 493534.

Viñao Frago, Antonio. «La escuela graduada: una nueva organización escolar y pedagógica». En Cien años de educación en España. En torno a la creación del Ministerio de Instrucción Pública y Bellas Artes, dirigido por Pedro Álvarez Lázaro, 363-88. Madrid: Ministerio de Educación, Cultura y Deporte, Fundación BBVA, 2001.

Viñao Frago, Antonio. "Templos de la patria, templos del saber: los espacios de la escuela y la arquitectura escolar». En Historia ilustrada de la escuela en España: dos siglos de perspectiva histórica, coordinado por Agustín Escolano Benito, 47-72. Salamanca: Fundación Germán Sánchez Ruipérez, 2006. 